\title{
Response to Rotenone Is Glucose-Sensitive in a Model of Human Acute Lymphoblastic Leukemia: Involvement of Oxidative Stress Mechanism, DJ-1, Parkin, and PINK-1 Proteins
}

\author{
Miguel Mendivil-Perez, Marlene Jimenez-Del-Rio, and Carlos Velez-Pardo \\ Neuroscience Research Group, Medical Research Institute, Faculty of Medicine, University of Antioquia (UdeA), \\ Calle 70 No. 52-21 and Calle 62 No. 52-59, Building 1, Room 412, Medellin, Colombia \\ Correspondence should be addressed to Carlos Velez-Pardo; carlos.velez@neurociencias.udea.edu.co
}

Received 17 December 2013; Accepted 27 March 2014; Published 11 May 2014

Academic Editor: Vittorio Calabrese

Copyright (C) 2014 Miguel Mendivil-Perez et al. This is an open access article distributed under the Creative Commons Attribution License, which permits unrestricted use, distribution, and reproduction in any medium, provided the original work is properly cited.

\begin{abstract}
To establish the effect of low (11 mM) and high $(55 \mathrm{mM})$ glucose concentrations (G11, G55) on Jurkat cells exposed to rotenone (ROT, a class 5 mitocan). We demonstrated that ROT induces apoptosis in Jurkat cells cultured in G11 by oxidative stress (OS) mechanism involving the generation of anion superoxide radical $\left(\mathrm{O}_{2}{ }^{--}, 68 \%\right)$ /hydrogen peroxide $\left(\mathrm{H}_{2} \mathrm{O}_{2}, 54 \%\right)$, activation of NF- $\kappa \mathrm{B}(32 \%)$, p53 (25\%), c-Jun (17\%) transcription factors, and caspase-3 (28\%), apoptosis-inducing factor (AIF, 36\%) nuclei translocation, c-Jun Nterminal kinase (JNK) activation, and loss of mitochondria transmembrane potential $\left(\Delta \Psi_{\mathrm{m}}, 62 \%\right)$ leading to nuclei fragmentation ( $\sim 10 \%$ and $\sim 40 \%$ stage I-II fragmented nuclei, resp.). ROT induces massive cytoplasmic aggregates of DJ-1 (93\%), and upregulation of Parkin compared to untreated cells, but no effect on PINK-1 protein was observed. Cell death marker detection and DJ-1 and Parkin expression were significantly reduced when cells were cultured in G55 plus ROT. Remarkably, metformin sensitized Jurkat cells against ROT in G55. Our results indicate that a high-glucose milieu promotes resistance against $\mathrm{ROT} / \mathrm{H}_{2} \mathrm{O}_{2}$-induced apoptosis in Jurkat cells. Our data suggest that combined therapy by using mitochondria-targeted damaging compounds and regulation of glucose (e.g., metformin) can efficiently terminate leukemia cells via apoptosis in hyperglycemic conditions.
\end{abstract}

\section{Introduction}

Acute lymphoblastic leukemia (ALL) is a type of hematologic disorder characterized by excess production of lymphoblast cells. ALL represents $12 \%$ of all leukemia cases, with a worldwide incidence projected to $1-4.75$ per 100,000 people [1]. Despite significant improvements in the treatment of ALL, pediatric ( 30\%) and adult (50-70\%) patients develop treatment-resistant disease. Furthermore, hyperglycemia during hyper-CVAD (fractionated cyclophosphamide, vincristine, doxorubicin, and dexamethasone) chemotherapy is associated with poor outcomes of ALL in about $35 \%$ of patients [2]. However, whether the action of new therapeutic compounds is different in hyperglycemic conditions versus normoglycemia in ALL patients is still unknown. Because leukemia cells are metabolically flexible, this condition might potentiate ALL cells to develop treatment resistance. At present, evasion of apoptosis-a type of programmed cell death-is one of the eight essential alterations in cellular physiology leading to malignancy [3]. Apoptosis displays morphological and biochemical hallmarks $[4,5]$ involving chromatin condensation, nuclear fragmentation, roundingup of the cell, reduction of cellular volume, and metabolic and energetic modifications of the mitochondria. Reactivation of apoptosis therefore appears as a prime strategy to eliminate cancer cells. Specifically, the identification of molecular pathways of cell death in ALL is an essential step towards therapeutic strategies. Before reaching this aim, the mechanism(s) must be unravelled.

Since mitochondria play essential roles in cellular metabolism, redox homeostasis, and the regulation of cell death, they represent an important target for anticancer therapy [6]. 
Interestingly, several natural compounds have been demonstrated to preferentially kill cancer cells with mitochondrial dysfunction [7]. Indeed, rotenone (ROT), a class 5 mitocan [8] that derives from the roots and backs of the Derris and Lonchorcarpus plant species, irreversibly binds to the Complex I (NADH: ubiquinone oxidoreductase) of the mitochondrial electron transport chain. This inhibition allows the reduction of molecular oxygen $\left(\mathrm{O}_{2}\right)$ to superoxide anion radical $\left(\mathrm{O}_{2}{ }^{--}\right)$by the iron-sulfur cluster $\mathrm{N} 2$, and subsequent generation of $\mathrm{H}_{2} \mathrm{O}_{2}$, most probably by the flavin mononucleotide $\left(\mathrm{FMNH}^{-}\right)$of Complex I [9]. ROT induces apoptosis in several cancerous cells [10-13]. However, whether the activation of executor protease caspase- $3[13$, 14] and the stress response c-Jun $\mathrm{N}$-terminal protein kinase (JNK) pathway $[12,15,16]$ occur in cancer cell lines exposed to ROT is not yet fully resolved. Moreover, ROT may [17] or may not [15] provoke cell death in pheochromocytoma PC12 cells. Therefore, the mechanism underlying ROT-induced apoptosis in cancer cells is not completely clear.

Recently, our group has provided evidence that oxidative stress (OS) generated by glucose-starvation (GS) induces apoptosis-inducing factor (AIF)- and caspase-3-dependent mitochondrial mechanisms of cell death in Jurkat cells (a model of human acute lymphoblastic leukemia) characterized by the activation of transcription factors such as nuclear factor-kappa B (NF- $\kappa \mathrm{B})$, p53, c-Jun; activation of c-Jun Nterminal kinase, AIF translocation to nuclei, mitochondria depolarization, and nuclear fragmentation as evidence of caspase-3 activation [18]. These observations have led us to postulate aminimal completeness of cell death signaling induced by OS as a mechanistic explanation of cancer cell demise [19]. However, whether ROT induces a similar cell death pathway in Jurkat cells and whether ROT action can be regulated by glucose are not yet clear.

Interestingly, Zhang et al. [20] have shown that p53 increases the transcription of PARKIN gene both in vitro and in vivo under OS. In turn, Parkin contributes to the role of p53 in regulating glucose metabolism and antioxidant defense by activating NF- $\kappa \mathrm{B}[21,22]$. Surprisingly, PARKIN and other genes such as PINK-1 (Phosphatase and tensin homolog (PTEN)-induced novel kinase-1) and DJ-1 have been associated with leukemia $[23,24]$. How these molecules interplay with p $53, \mathrm{NF}-\kappa \mathrm{B}$, and AIF in OS-induced apoptosis in Jurkat cells under different metabolic conditions (e.g., glucose) is not yet established.

On the assumption that a high-glucose milieu may interfere with the cell response to drugs, we investigated the ROTinduced toxicity in low (11 mM, G11) and high (55 mM, G55) glucose concentrations that mimic in vivo conditions of normoglycemia and hyperglycemia, respectively. To get insight, we sought (i) to investigate whether ROT induces apoptosis in Jurkat cell line; (ii) to determine whether ROT treatment induces OS through $\mathrm{O}_{2}{ }^{\cdot-} / \mathrm{H}_{2} \mathrm{O}_{2}$, caspase-3, AIF, and the activation of proapoptotic transcription factors NF- $\kappa \mathrm{B}, \mathrm{p} 53$, and c-Jun. We also investigated (iii) whether ROT differentially alters DJ-1, Parkin, and PINK-1 protein expression in Jurkat cells in both glucose conditions. The present investigation suggests that combined therapy by using mitocan compounds and metformin might efficiently terminate leukemia cells via apoptosis in hyperglycemic ALL patients.

\section{Materials and Methods}

3,3'-dihexyloxacarbocyanine iodide $\left(\mathrm{D}_{i} \mathrm{OC}_{6}(3)\right.$, Catalog number D-273), ammonium pyrrolidinedithiocarbamate (PDTC, Catalog number 548000), and 1,9-pyrazoloanthrone (SP600125, Catalog number 420119) were acquired from Calbiochem. Dichlorofluorescein diacetate $\left(\mathrm{DCFH}_{2}-\mathrm{DA}\right)$ was obtained from Invitrogen. All other reagents were purchased from Sigma-Aldrich.

2.1. Jurkat T Leukemia Cell Culture. Jurkat clone E6-1 (ATCC Catalog number TIB-152) was cultured according to supplier's indications.

\subsection{Experiments with Jurkat Leukemia Cell Line}

2.2.1. Morphological Assessment of Cell Death by Fluorescent Microscopy. The cell suspension ( $1 \mathrm{~mL}$, final volume) was exp-osed to increasing $\mathrm{ROT}(0-100 \mu \mathrm{M})$ concentrations freshly prepared in RPMI-1640 medium either supplemented with $11 \mathrm{mM}$ (hereafter $11 \mathrm{G}$ ) or $55 \mathrm{mM}$ (hereafter 55G) glucose in the absence or presence of different products of interest for $1-24 \mathrm{~h}$ at $37^{\circ} \mathrm{C}$. Cells were incubated with $1 \mu \mathrm{L}$ acridine orange $(\mathrm{AO}, 0.1 \mathrm{mg} / \mathrm{mL}) /$ ethidium bromide (EB, $0.1 \mathrm{mg} / \mathrm{mL}) /$ Hoechst $(\mathrm{H}, 3 \mu \mathrm{g} / \mathrm{mL})$ staining. Quantification of apoptotic morphology was performed by fluorescent microscopy analysis. The apoptotic indexes were assessed 3 times in independent experiments blind to experimenter.

\subsubsection{Evaluation of Intracellular Reactive Oxygen Species} (ROS). Superoxide anion radicals were evaluated as described in Ref Quantification of nitroblue tetrazolium positive cells $\left(\mathrm{NBT}^{+}\right)$was performed blind to experimenter. The assessment was repeated 3 times in independent experiments. Hydrogen peroxide $\left(\mathrm{H}_{2} \mathrm{O}_{2}\right)$ was determined with $2^{\prime}, 7^{\prime}$ dichlorofluorescin diacetate $(5 \mu \mathrm{M})$, using a flow cytometer Beckman Coulter Epics XL and fluorescent microscopy analysis, respectively. The assessment was repeated 3 times in independent experiments.

\subsubsection{Analysis of Mitochondrial Membrane Potential $\left(\Delta \Psi_{m}\right)$ by} Flow Cytometry and Fluorescent Microscopy. Jurkat cell line was treated as described above. Then, cells $\left(1 \times 10^{5}\right)$ were incubated with cationic lipophilic $(10 \mathrm{nM})$ and $(1 \mu \mathrm{M}) \operatorname{DiOC}_{6}(3)$ final concentration for $20 \mathrm{~min}$ at RT in the dark. Cells were then analyzed using flow cytometer Beckman Coulter Epics $\mathrm{XL}$ and fluorescent microscopy analysis, respectively. The assessment was repeated 3 times in independent experiments.

\subsection{Immunocytochemistry Detection of Transcription Fac-} tor NF- $\kappa$ B, p53, c-Jun, Caspase-3, Apoptosis-Inducing Factor (AIF), DJ-1, Parkin, and PINK-1. The Santa Cruz Biotechnology (SCB) supplier protocol goat ABC staining System 
(Catalog number sc-2023) was followed for the immunocytochemistry using primary goat polyclonal antibodies NF$\kappa$ B p65 (C-20)-G (Catalog number sc-372-G), p53 (FL393) (Catalog number sc-6243-G), p-(Ser73)-c-Jun (Catalog number sc-7981), caspase-3 (Catalog number sc-22171) and AIF (Catalog number sc-9417) and SCB protocol goat ABC staining System (Catalog number SC-2018) was followed for the immunocytochemistry using primary antibodies DJ-1 (FL189) (Catalog number sc-32874), Parkin (H300) (Catalog number sc-30130) and PINK-1 (H300) (Catalog number sc33796). The cells were immune-stained and diaminobenzidine positive $\left(\mathrm{DAB}^{+}\right)$cells were quantified blind to experimenter.

2.4. Detection of DJ-1, Parkin, and PINK-1 by Flow Cytometry. After each treatment with or without ROT in G11 or G55, cells $\left(1 \times 10^{5}\right)$ were fixed in $80 \%$ ethanol and stored at $-20^{\circ} \mathrm{C}$ overnight. Then after that, cells were washed with PBS and permeabilized with $0.2 \%$ triton $\mathrm{X}-100$ plus $1.5 \%$ bovine serum albumin (BSA) in phosphate buffer solution (PBS) for $30 \mathrm{~min}$. Cells were washed and incubated with $20 \mu \mathrm{g} / \mathrm{mL}$ (diluted in PBS containing 0.1\% BSA) primary antibody DJ-1 (FL189) (Catalog number sc-32874), Parkin (H300) (Catalog number sc-30130), and PINK-1 (H300) (Catalog number sc33796 ) for $2 \mathrm{~h}$ at $37^{\circ} \mathrm{C}$ under agitation. Subsequently, the cells were washed and incubated with FITC-conjugated rabbitantigoat-IgG antibody (Catalog number sc-2012; $20 \mu \mathrm{g} / \mathrm{mL}$ ) for $30 \mathrm{~min}$ at RT in the dark. After washing with PBS, the cells were resuspended in $500 \mu \mathrm{L}$ of PBS. Analysis was performed on a Flow Cytometer Beckman Coulter Epics XL. Jurkat cells without primary antibodies served as negative control. Results of the mean fluorescence intensity (MFI) of Jurkat cells were compared between controls and treatments. For assessment purpose, it was acquired 10,000 events and assessment was performed 3 times in independent experiments. Quantitative data were obtained using Windows Multiple Document Interface for Flow Cytometry 2.8 (WinMDI 2.8) software (http://facs.scripps.edu/software.html).

2.5. Evaluation of Signal Inhibitors on Cells Exposed to Rotenone. The cell suspension ( $1 \mathrm{~mL}$, final volume) was treated with $(50 \mu \mathrm{M})$ ROT in glucose (11G) and inhibitor reagents at the concentration listed in Table 1 at $37^{\circ} \mathrm{C}$ for $24 \mathrm{~h}$. After this time, cells were evaluated for apoptotic features (nuclei morphology and $\Delta \Psi_{\mathrm{m}}$ ) by fluorescence microscopy or flow cytometry, as described in previous sections. The assessment was repeated 3 times in independent experiments.

2.6. Statistical Analysis. Data are means \pm S.D. of three independent experiments. One-way ANOVA analyses with Bonferroni or Games-Howell post hoc comparison were calculated with SPSS 18 software. A $P$ value of ${ }^{*} P<0.05$ and ${ }^{* *} P<0.001$ was considered significant.

2.7. Photomicrography. The light microscopy or fluorescent photomicrographs were taken using a Zeiss (Axiostart 50) microscope equipped with a Canon PowerShot G5 digital camera.
TABLE 1: Oxidative stress and signalling molecules (NF- $\kappa$ B, c-Jun, p53, and caspase-3) are involved in rotenone (ROT)-induced apoptosis in Jurkat T cells.

\begin{tabular}{lcc}
\hline Treatment/assay & $\begin{array}{c}\mathrm{AO} / \mathrm{EB} / \mathrm{H} \\
(\%)\end{array}$ & $\begin{array}{c}\mathrm{PI}^{-} / \mathrm{DiOC}_{6}(3)^{+} \\
(\%)\end{array}$ \\
\hline Untreated & $1 \pm 0^{* *}$ & $98 \pm 1^{* *}$ \\
ROT $(50 \mu \mathrm{M})$ & $50 \pm 3^{* *}$ & $51 \pm 2^{* *}$ \\
PDTC $(10 \mathrm{nM})$ & $1 \pm 0^{* *}$ & $97 \pm 1^{* *}$ \\
PDTC $(10 \mathrm{nM})+\operatorname{ROT}(50 \mu \mathrm{M})$ & $9 \pm 3^{* *}$ & $89 \pm 3^{* *}$ \\
PFT $(50 \mathrm{nM})$ & $1 \pm 0^{* *}$ & $98 \pm 1^{* *}$ \\
PFT $(50 \mathrm{nM})+\operatorname{ROT}(50 \mu \mathrm{M})$ & $11 \pm 2^{* *}$ & $87 \pm 3^{* *}$ \\
SP600125 $(1 \mu \mathrm{M})$ & $2 \pm 1^{* *}$ & $97 \pm 1^{* *}$ \\
SP600125 $(1 \mu \mathrm{M})+\operatorname{ROT}(50 \mu \mathrm{M})$ & $6 \pm 2^{* *}$ & $93 \pm 3^{* *}$ \\
NSCI $(10 \mu \mathrm{M})$ & $1 \pm 0^{* *}$ & $98 \pm 1^{* *}$ \\
NSCI $(10 \mu \mathrm{M})+\operatorname{ROT}(50 \mu \mathrm{M})$ & $5 \pm 1^{* *}$ & $94 \pm 2^{* *}$ \\
NAC $(1 \mathrm{mM})$ & $1 \pm 0^{* *}$ & $98 \pm 1^{* *}$ \\
NAC $(1 \mathrm{mM})+\operatorname{ROT}(50 \mu \mathrm{M})$ & $10 \pm 3^{* *}$ & $89 \pm 1^{* *}$ \\
\hline
\end{tabular}

Jurkat cells $\left(1 \times 10^{6}\right.$ cells $\left./ \mathrm{mL}\right)$ were exposed to ROT $(50 \mu \mathrm{M})$ in absence or presence of PDTC $(10 \mathrm{nM})$, pifithrin- $\alpha$ (PFT, $50 \mathrm{nM})$, SP600125 $(1 \mu \mathrm{M})$ and NSCI $(10 \mu \mathrm{M})$ signaling inhibitors, and NAC $(1 \mathrm{mM})$ at $37^{\circ} \mathrm{C}$ for $24 \mathrm{~h}$. Cells were then evaluated for apoptotic nuclei morphology and mitochondrial membrane potential, as described in Material and Methods. The percentage of positive $\mathrm{AO} / \mathrm{EB} / \mathrm{Hoechst}$ staining and $\mathrm{PI}^{-} / \mathrm{DiOC}_{6}(3)^{+}$of Jurkat cells treated with or without ROT is expressed as a mean percentage \pm S.D. from three independent experiments. ${ }^{* *} P<0.001$.

\section{Results}

3.1. Rotenone (ROT) Induces Nuclei Morphology Distinctive of Apoptosis in Jurkat T Cells Associated with Superoxide Anion Radical $\left(\mathrm{O}_{2}{ }^{\cdot-}\right)$ /Hydrogen Peroxide $\left(\mathrm{H}_{2} \mathrm{O}_{2}\right)$ Generation and Impairment of Mitochondrial Membrane Potential $\left(\Delta \Psi_{m}\right)$. We initially evaluated the effect of ROT in Jurkat cells under standard culture conditions (glucose medium containing $11 \mathrm{mM}$ glucose, G11). As shown in Figure 1, ROT induced generation of $\mathrm{O}_{2}{ }^{--}$(Figure $1(\mathrm{a})$ ) in a concentrationdependent fashion up to $50 \mu \mathrm{M}$ (from $25 \%$ to $58 \%$ ), declining to $\sim 20 \% \mathrm{FORMz}^{+}$at $100 \mu \mathrm{M}$ (Figure $1(\mathrm{~g})$ ). On the contrary, ROT generated $\mathrm{H}_{2} \mathrm{O}_{2}$ (Figure $1(\mathrm{~b})$ ) almost constantly (48$\left.55 \% \mathrm{DCF}^{+}\right)$up to $50 \mu \mathrm{M}$, but its generation was reduced by $\sim 30 \%$ at $100 \mu \mathrm{M}$ (Figures $1(\mathrm{e}), 1(\mathrm{~g})$ ). Concurrently, ROT provoked loss of $\Delta \Psi_{\mathrm{m}}$ (Figures $1(\mathrm{c})$ and $1(\mathrm{f})$ ) and nuclei condensation/fragmentation (Figure $1(\mathrm{~d})$ ) in Jurkat cells in a concentration fashion (Figures $1(\mathrm{f})$ and $1(\mathrm{~g})$ ), as assessed by fluorescence microscopy (Figures $1(\mathrm{c})$ and $1(\mathrm{~d})$ ) and flow cytometry (Figures 1(f), 1(g), and 6(a)), respectively. Because $50 \mu \mathrm{M}$ ROT provoked $\sim 50 \%$ nuclei fragmentation $/ \Delta \Psi_{\mathrm{m}}$ depolarization and it is an end-point for $\mathrm{O}_{2}{ }^{--} / \mathrm{H}_{2} \mathrm{O}_{2}$ generation, this concentration was selected for further experiments. Of note, the antioxidant $N$-acetyl-cysteine (NAC, $1 \mathrm{mM}$ ) significantly reduced the proapoptotic effect of ROT in Jurkat cells (Table 1).

3.2. ROT Induces Apoptosis in Jurkat T Cells Associated with NF- $\kappa$, p53 and c-Jun Transcription Factors, Caspase-3 Activation, and Apoptosis-Inducing Factor (AIF). To evaluate the participation of signaling molecules in ROT-induced apoptosis, Jurkat cells were either preincubated one hour 


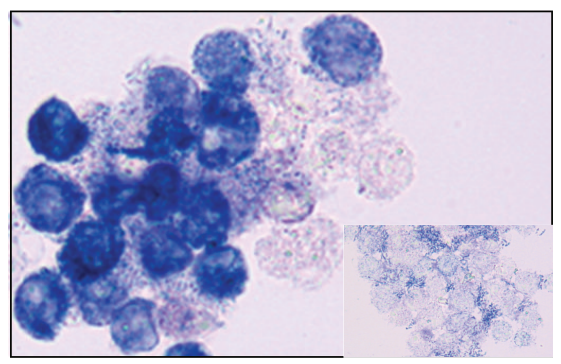

(a)

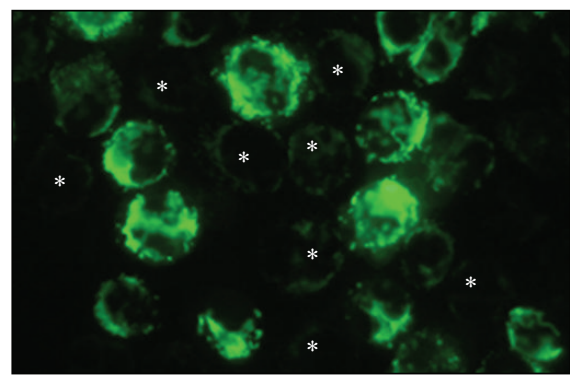

(c)

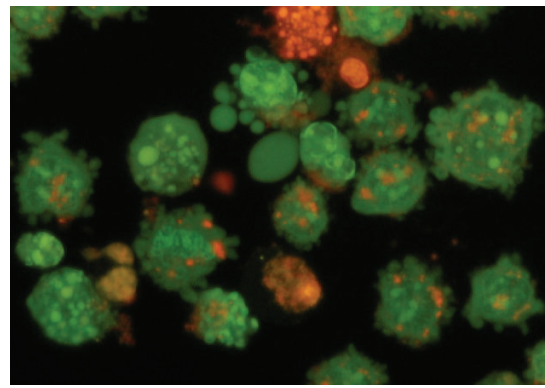

$\left(d^{\prime}\right)$

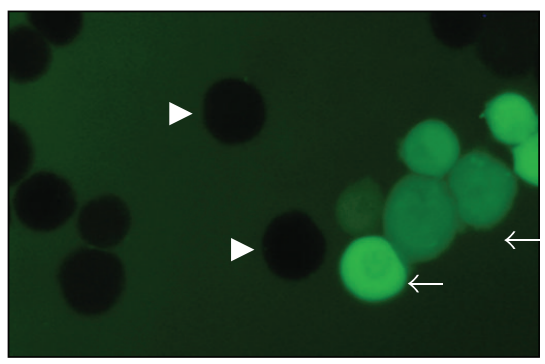

(b)

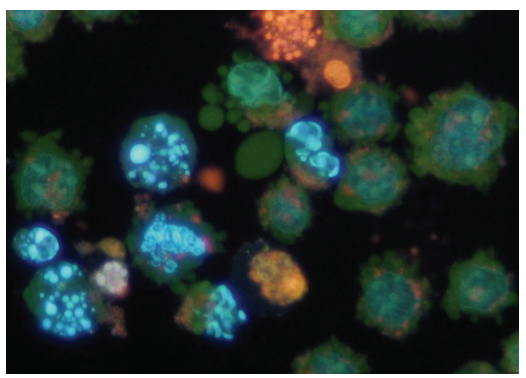

(d)

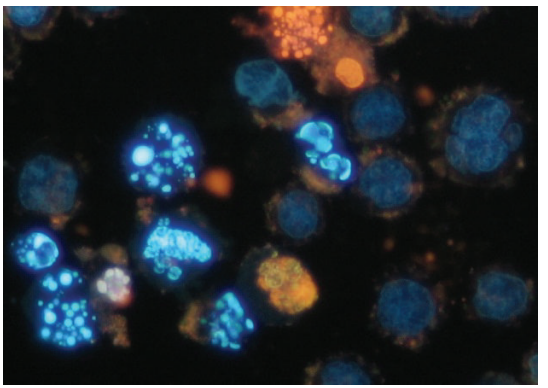

$\left(d^{\prime \prime}\right)$
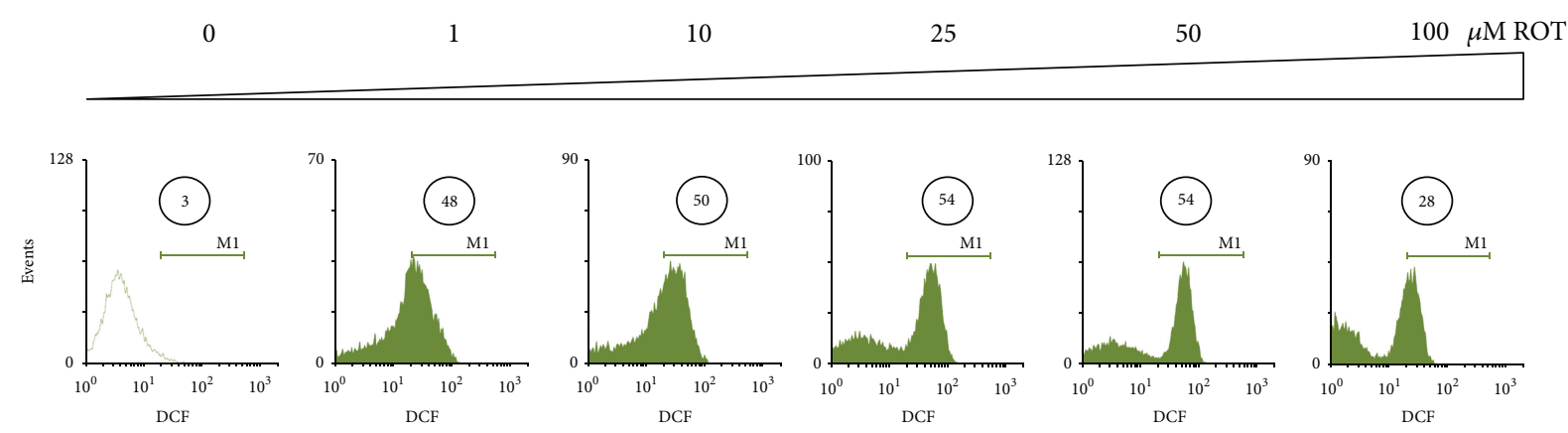

(e)
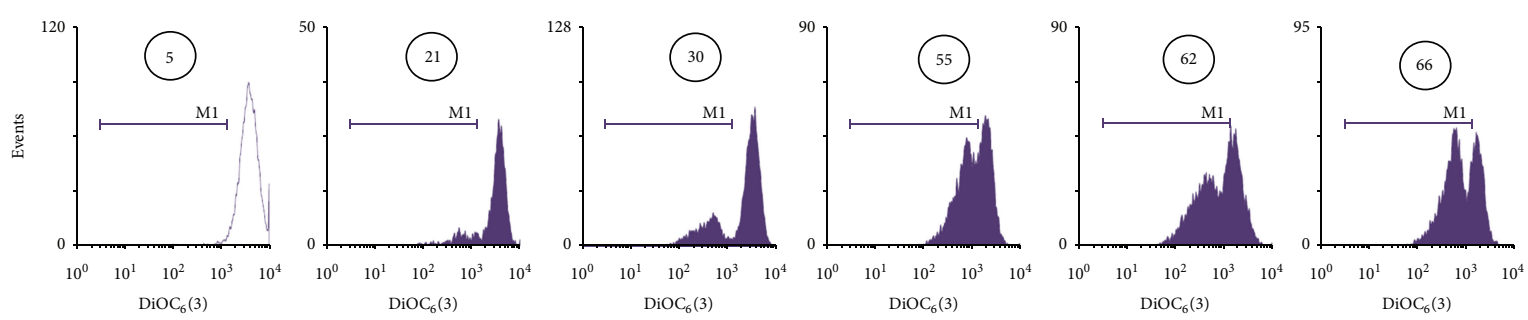

(f)

FIgUre 1: Continued. 


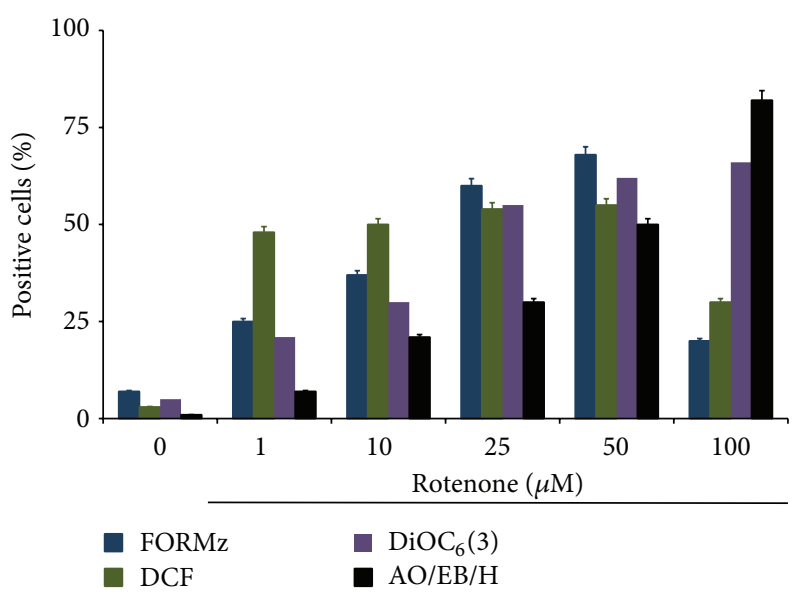

(g)

FIGURE 1: Rotenone (ROT) induces reactive oxygen species, mitochondrial depolarization, and chromatin condensation/nuclei fragmentation in Jurkat T leukemia cells. (a) Representative light photomicrography showing positive nitroblue tetrazolium $\left(\mathrm{NBT}^{+}\right)$stained blue-purple precipitate cells (i.e., formazan: FORMz) as positive $\mathrm{O}_{2}{ }^{--}$generation in Jurkat cells cultured in basal glucose medium containing $11 \mathrm{mM}$ glucose (G11) treated with $(50 \mu \mathrm{M})$ ROT for $24 \mathrm{~h}$. Inset: untreated cells showing negative NBT staining. (b) Fluorescent photomicrography (ex. 450$490 \mathrm{~nm}$, em. $515 \mathrm{~nm}$ ) illustrating positive $2^{\prime}, 7^{\prime}$-dichlorofluorescein (DCF, arrows) and negative (arrowheads) stained cells as positive/negative $\mathrm{H}_{2} \mathrm{O}_{2}$ production from Jurkat T cells cultured in G11 treated with $(50 \mu \mathrm{M})$ ROT for $24 \mathrm{~h}$. (c) Representative fluorescent photomicrography (ex. $450-490 \mathrm{~nm}$, em. $515 \mathrm{~nm}$ ) illustrates positive green fluorescent stained cells as $\mathrm{DiOC}_{6}(3)$ high-polarized and low-polarized mitochondria and depolarized mitochondria (asterisk) from treated cells with $(50 \mu \mathrm{M})$ ROT in G11 for $24 \mathrm{~h}$. (d) Representative (merge image) fluorescent photomicrography showing treated cells with $(50 \mu \mathrm{M})$ ROT in G11 for $24 \mathrm{~h}$ with condensed chromatin (stage I nuclei morphology) and DNA fragmentation (stage II nuclei morphology) analyzed by either AO/EB ((d'), ex. 450-490 nm, em. $515 \mathrm{~nm})$, Hoechst staining ((d") , ex. $354 \mathrm{~nm}$, em. $442 \mathrm{~nm}$ ). (e) Representative histograms showing the percentage of dichlorofluorescein positive (DFC ${ }^{+}$) cells. (f) Percentage of DiOC 6 (3) low $\left(\mathrm{DiOC}_{6}(3)^{-}\right)$cells exposed to increasing concentration of ROT $(0-100 \mu \mathrm{M})$, assessed at $24 \mathrm{~h}$. (g) The percentage of positive FORMz, DCF, $\mathrm{DiOC}_{6}(3)$, and $\mathrm{AO} / \mathrm{EB} / \mathrm{Hoechst}$ cells exposed to increasing concentration of ROT $(0-100 \mu \mathrm{M})$ is expressed as a mean percentage \pm S.D. from three independent experiments. Magnification ((a)-(d)) 1000x. Magnification inset (a) 600x.

with PDTC (10 nM, an inhibitor of NF- $\kappa \mathrm{B})$, PFT $(50 \mathrm{nM}$, a specific inhibitor of p53), SP600125 (1 $1 \mu \mathrm{M}$, a specific inhibitor of c-Jun N-terminal kinase), or NSCI $(10 \mu \mathrm{M}$, a specific inhibitor of caspase-3) prior to incubation with ROT $(50 \mu \mathrm{M})$ in G11 for $24 \mathrm{~h}$. All the specific pharmacological inhibitors moderately reduced the ROT-induced apoptotic effect and the $\Delta \Psi_{\mathrm{m}}$ compared to control (Table 1). The participation of the transcription factors, caspase-3, and AIF was also evaluated by immunohistochemistry. As shown in Figure 2, ROT clearly induced $\mathrm{DAB}^{+}$nuclei staining of the active form of NF- $\kappa \mathrm{B}$ (Figure 2(b)), p53 (Figure 2(d)), c-Jun (Figure 2(f)), CASP-3 (Figure 2(h)), and AIF (Figure 2(j)) compared to untreated cells (Figures 2(a), 2(c), 2(e), 2(g), and 2(i)) with a different percentage of detection (Figure 2, insets). Noticeably, the morphology of the stained $\mathrm{DAB}^{+}$cells corresponded exactly to the nuclei fragmentation observed under fluorescent microscopy (see Figures 1(d) and 2(b), 2(d), $2(\mathrm{f}), 2(\mathrm{~h})$, and $2(\mathrm{j}))$.

3.3. ROT Induces DJ-1 Cytoplasmic Accumulation and Parkin Overexpression but Has No Influence on PINK-1 Protein. Next, we examined whether DJ-1, Parkin, and PINK-1 were involved in ROT-induced cell death. As shown in Figure 3, ROT provoked massive cytoplasmic $\mathrm{DAB}^{+}$aggregates of DJ-1 (93\%, Figure 3(b)) compared to untreated cells (1\%, Figure 3(a)), whereas Parkin and PINK-1 presented moderate or scarce $\mathrm{DAB}^{+}$aggregates, respectively (Figures $3(\mathrm{~d})$ and 3(f)) compared to untreated cells (Figures 3(c) and 3(e)), as assessed by immunocytochemistry. These observations were further confirmed by flow immunocytometry (Figures 4(a), 4(c), and 4(d)). Indeed, cells exposed to ROT showed low DJ-1 mean fluorescence intensity (MFI) units, reflecting cytoplasmic high molecular aggregates, compared to untreated cells (Figure 4(a)). In contrast, cells exposed to ROT showed higher Parkin MFI, reflecting either overexpression or the presence of Parkin monomers rather than aggregates, compared to untreated cells (Figure 4(c)). PINK1 MFI protein levels were unaffected in cells under ROT exposure (Figure 4(e)).

3.4. High Glucose Reduces ROT-Induced Apoptosis Markers in Jurkat T Cells. Since glucose metabolism is upregulated in cancer cells, we were interested in determining the extent to which glucose modulates ROT-induced apoptosis response in Jurkat cells. We characterized chromatin condensation as stage I nuclei morphology composed of high molecular weight DNA and nuclear fragmentation as stage II nuclei morphology composed of low molecular weight DNA, chromatin condensation in highly packed round masses of nuclei morphology induced by $(50 \mu \mathrm{M})$ ROT under $(55 \mathrm{mM})$ glucose concentration (i.e., G55). As shown in Figure 5(a), ROT induced lower apoptotic nuclei morphology (20\%) with a different stage I ( $\sim 5 \%)$ and stage II $(\sim 15 \%)$ nuclei morphology proportion under G55 than in cells cultured under G11 plus 


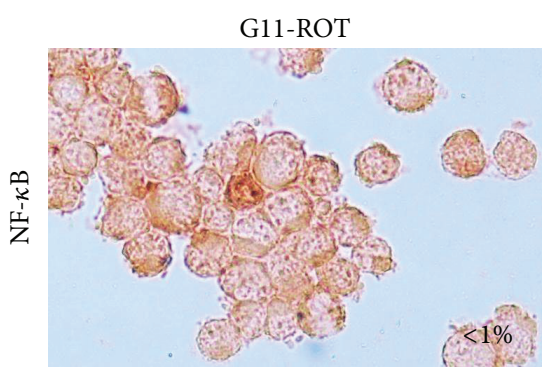

(a)

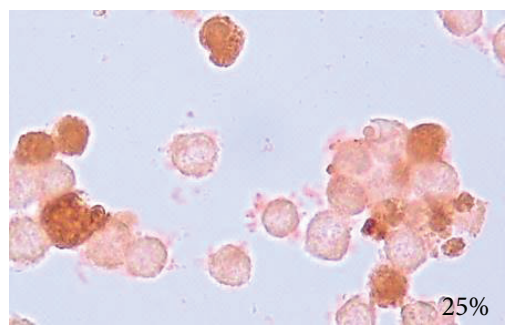

(d)

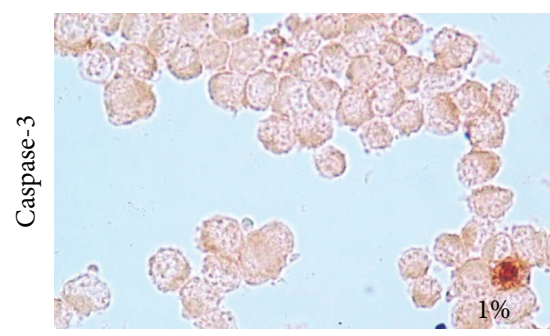

$(\mathrm{g})$

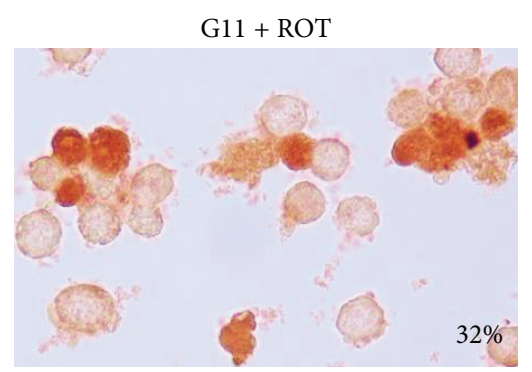

(b)

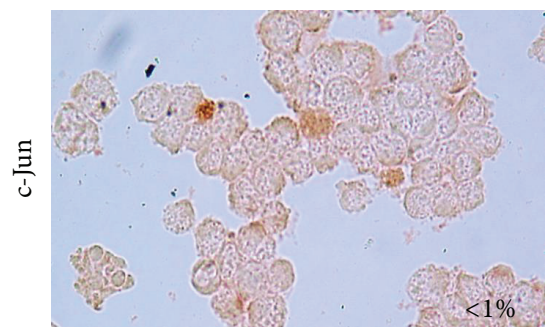

(e)

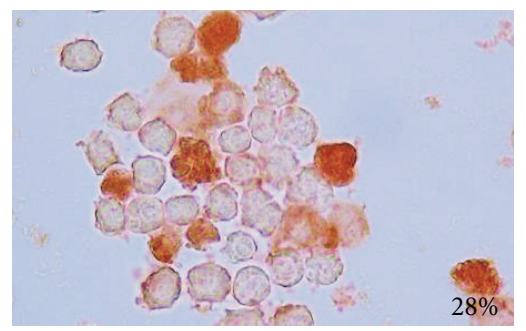

(h)

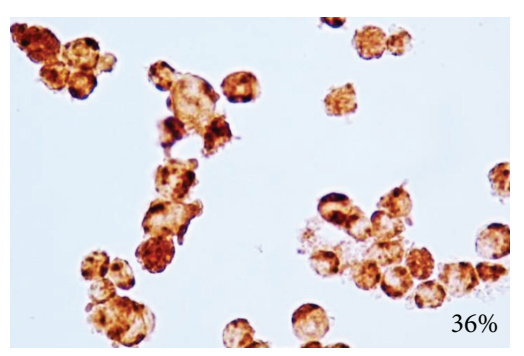

(j)

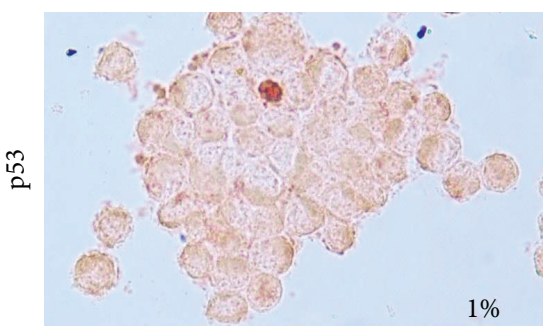

(c)

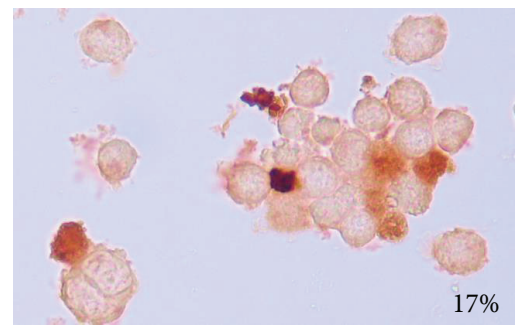

(f)

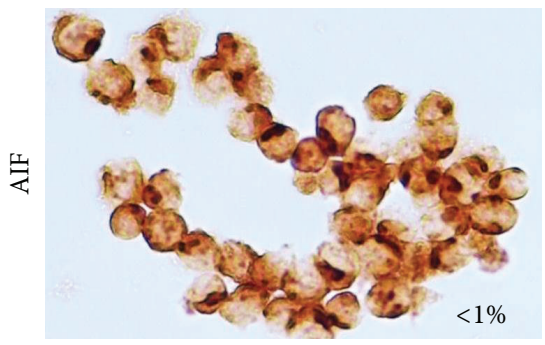

(i)

FIGURE 2: Rotenone induces activation of the transcription factors, apoptosis-inducing factor, and caspase-3 in Jurkat T cells. Leukemia cells were left untreated ((a), (c), (e), (g), and (i)) or exposed to $(50 \mu \mathrm{M})$ ROT ((b), (d), (f), (h), and (j)) in G11 medium for $24 \mathrm{~h}$. Cells were stained with anti-NF- $\kappa$ B-p65 ((a) and (b)), anti-p53 ((c) and (d)), anti-c-Jun ((e) and (f)), anti-caspase-3 ((g) and (h)), and anti-AIF ((i) and (j)), antibodies according to procedure described in Materials and Methods. Notice that positive nuclei (dark brown color) reflect their nuclear translocation/activation and appear to correlate with the apoptotic nuclear morphology. Magnification 1000x ((a)-(j)). Insets: percentage of positive DAB staining.

ROT (50\% apoptotic nuclei: $10 \%$ stage I, $40 \%$ stage II nuclei morphology), as evaluated by triple $\mathrm{AO} / \mathrm{EB}$ and Hoechst staining techniques (Figure $1(\mathrm{~d})$ ). These observations were confirmed by DNA fragmentation (Figure 5(b)) and $\Delta \Psi_{\mathrm{m}}$ depolarization (Figure 5(c)), as evaluated by flow cytometer. Of note, the $\Delta \Psi_{\mathrm{m}}$ was significantly preserved in cells exposed to ROT in G55 compared with cells exposed to ROT in G11. We then established generation of ROS, activation of signaling (NF- $\kappa \mathrm{B}, \mathrm{p} 53)$, executer (caspase-3, AIF), and mitochondrial maintenance (DJ-1, Parkin, and PINK-1) molecules under G55 condition. As noted in Figure 5(d), cells exposed to ROT generated high levels of $\mathrm{H}_{2} \mathrm{O}_{2}$, shown as MFI, irrespective of glucose medium concentration. Likewise, cells under G55 + ROT showed a low percentage of NF- $\kappa \mathrm{B}$ (Figure 6(b)), p53 (Figure 6(d)), c-Jun (Figure 6(f)), caspase3 (Figure 6(h)) activation, and AIF (Figure 6(j)) compared with cells under G55 alone (Figures 6(a), 6(c), 6(e), 6(g), and 6(i)). Furthermore, cells exposed to G55 plus ROT also displayed low percentage of DJ-1 (Figures 4(b) and 7(b)) and Parkin (Figures 4(d) and 7(d)), evaluated as $\mathrm{DAB}^{+}$cells and 


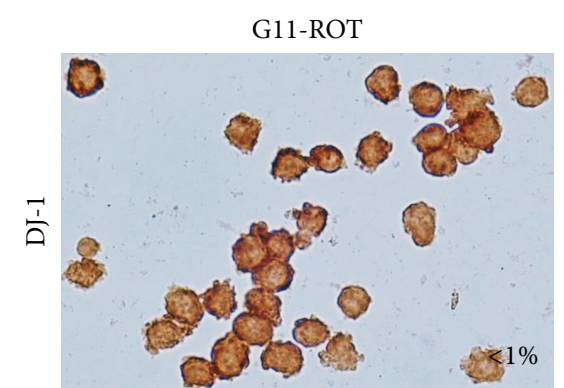

(a)

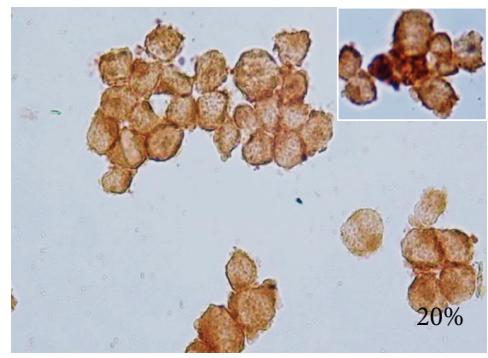

(d)

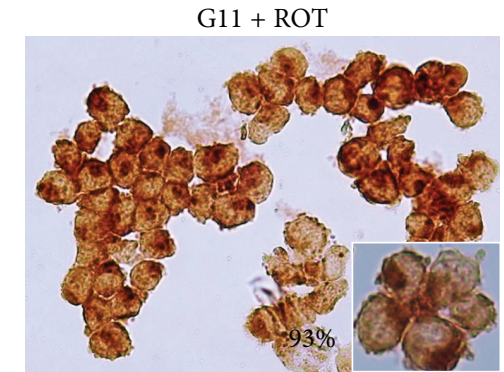

(b)

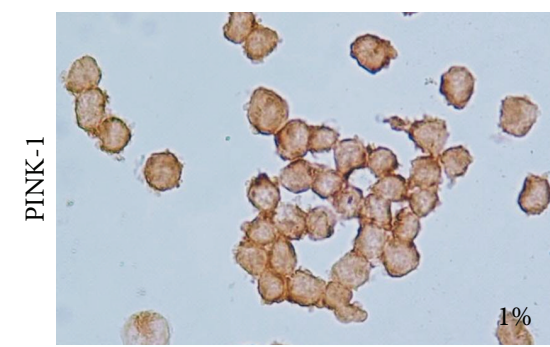

(e)

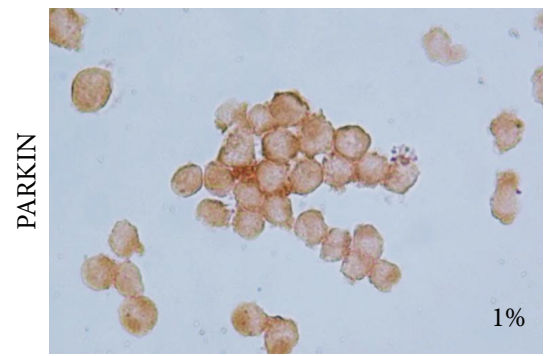

(c)

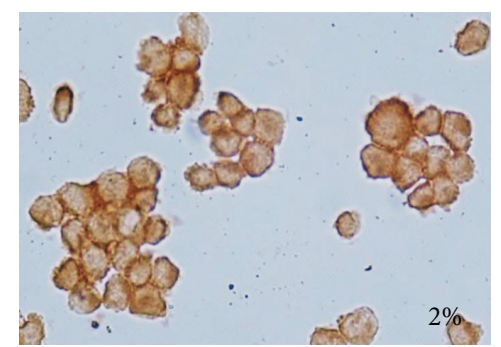

(f)

Figure 3: Rotenone induces differential effect on DJ-1, Parkin, and PINK-1 proteins (chromofore immunohistochemistry assay). Leukemia cells were left untreated ((a), (c), and (e)) or exposed to $(50 \mu \mathrm{M})$ ROT ((b), (d), and (f)) in G11 medium for $24 \mathrm{~h}$. Cells were stained with anti-DJ-1 ((a) and (b)), anti-Parkin ((c) and (d)) and anti-PINK-1 ((e) and (f)) antibodies, as described in Materials and Methods. Notice that positive aggregates (dark brown color) reflect their cytoplasmic localization. Magnification 800x ((a)-(f)). Insets: percentage of positive DAB staining.

MFI units, respectively. PINK-1 showed similar percentages of $\mathrm{DAB}^{+}$cells and MFI units in cells under G55 and ROT (Figures $4(\mathrm{f})$ and $7(\mathrm{f})$ ).

\subsection{Metformin Sensitizes Jurkat Cells against ROT-Induced} Toxicity. Since metformin, a recognized glucose-lowering drug, has been shown to strongly interfere with survival and proliferation on Jurkat cells [25], we wanted to know whether metformin affected the toxicity of ROT in Jurkat cells under G55. As shown in Figure 8(e), metformin increases $\sim 3$-fold ROT-induced apoptosis in Jurkat cells in G55, as assessed by $\mathrm{AO} / \mathrm{EB} /$ Hoechst staining (Figures $8(\mathrm{a})-8(\mathrm{~d})$ ), DNA fragmentation (Figure $8(\mathrm{f})$ ), and $\Delta \Psi_{\mathrm{m}}$ depolarization assay (Figure $8(\mathrm{~g})$ ).

\section{Discussion}

Several data suggest that ROT induces death through enhancing $\mathrm{O}_{2}{ }^{--} / \mathrm{H}_{2} \mathrm{O}_{2}$ production by mitochondrial complex I [9] in cancer cells $[13,26]$; however, the mechanism by which ROT provokes cell death remains controversial (i.e., OS versus the impairment of $\Delta \Psi_{\mathrm{m}}$ and decline of energy production). Here, we provide in vitro evidence supporting a role for OS in ROTinduced apoptosis in Jurkat cells under 2 different glucose $(G)$ milieus: $11 \mathrm{mM}$ (G11) and $55 \mathrm{mM}$ (G55) glucose, as a model of normoglycemia and hyperglycemia in ALL, respectively. Mechanistically, ROT-induced apoptosis complies with the model of minimal completeness of cell death signaling
[19]. Effectively, we confirm that ROT (1-100 $\mu \mathrm{M})$ produces $\mathrm{O}_{2}{ }^{\circ-}$ and $\mathrm{H}_{2} \mathrm{O}_{2}$ in Jurkat cells according to the reduction of NBT to formazan and $\mathrm{DFCH}_{2}$ oxidation to fluorescent DCF assay, respectively. Furthermore, ROT generated $\mathrm{O}_{2}{ }^{-{ }^{-}}$ in a concentration-dependent fashion up to $50 \mu \mathrm{M}$ with a marked decreased at $100 \mu \mathrm{M}$; however, $\mathrm{H}_{2} \mathrm{O}_{2}$ was constantly produced up to $50 \mu \mathrm{M}$ with a significant reduction at $100 \mu \mathrm{M}$. Why did $\mathrm{O}_{2}{ }^{-}$and $\mathrm{H}_{2} \mathrm{O}_{2}$ levels decrease at $100 \mu \mathrm{M}$ ROT concentration compared with lower ROT concentrations? A possible explanation is that $100 \mu \mathrm{M}$ ROT is high enough concentration to generate high amounts of $\mathrm{O}_{2}{ }^{\circ-}$, which can dismutate enzymatically or nonenzymatically into $\mathrm{H}_{2} \mathrm{O}_{2}$ at early ROT exposure with no apparent effect on nuclei morphology and $\Delta \Psi_{\mathrm{m}}$. Once produced, $\mathrm{H}_{2} \mathrm{O}_{2}$ triggers nuclei and $\Delta \Psi_{\mathrm{m}}$ damage. By $24 \mathrm{~h}, \mathrm{O}_{2} / \mathrm{O}_{2}{ }^{-} / \mathrm{H}_{2} \mathrm{O}_{2}$ have been exhausted, destroyed, or decomposed concomitantly with maximal percentage of cell nuclei condensation/fragmentation and loss of $\Delta \Psi_{\mathrm{m}}$. Because $50 \mu \mathrm{M}$ ROT provoked $\sim 50 \%$ nuclei fragmentation $/ \Delta \Psi_{\mathrm{m}}$ depolarization, and it was an end-point for $\mathrm{O}_{2}{ }^{--} / \mathrm{H}_{2} \mathrm{O}_{2}$ generation, this concentration was selected for testing. Interestingly, $50 \mu \mathrm{M}$ ROT generates high amounts of ROS in G11 and G55. This observation implies that ROT produces $\mathrm{O}_{2}{ }^{--}$and $\mathrm{H}_{2} \mathrm{O}_{2}$ independently of glucose concentration. However, the specific behavior of effector (NF- $\kappa \mathrm{B}$, p53, c-Jun), executer (caspase-3, AIF), antioxidant (DJ-1), and mitochondrial related (Parkin, PINK-1) molecules changed according to milieu condition. We found that ROT induces chromatin condensation (stage I) and nuclei fragmentation (stage II) concomitantly with loss of $\Delta \Psi_{\mathrm{m}}$, nuclear localization 


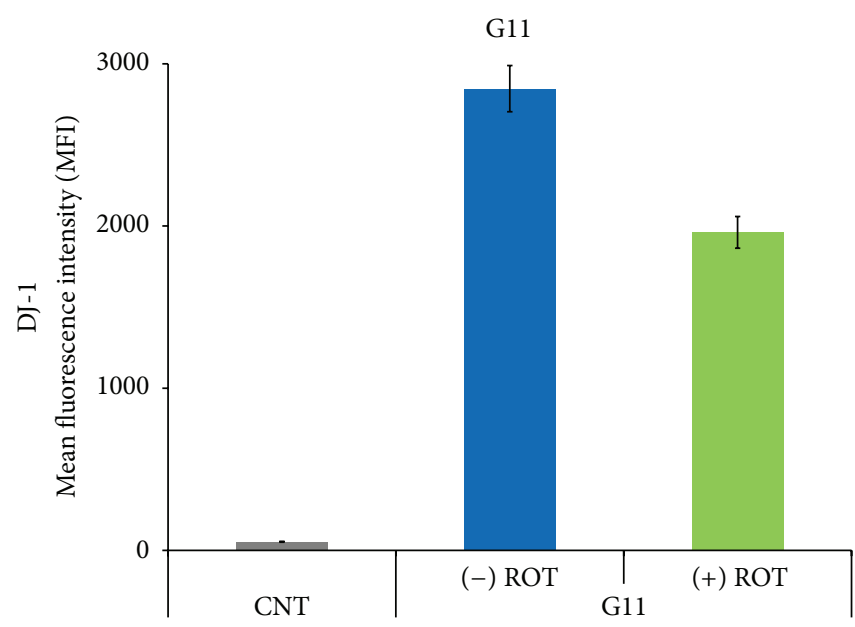

(a)

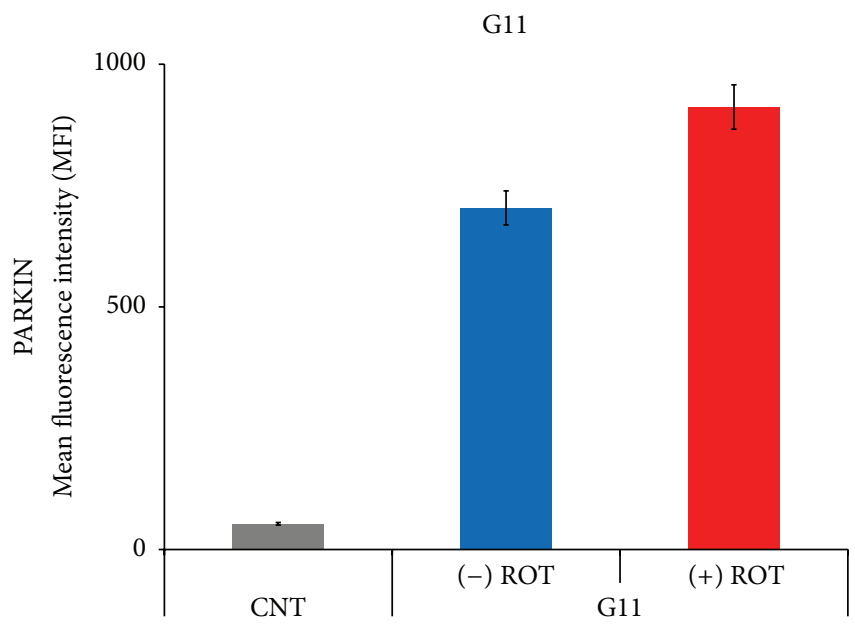

(c)

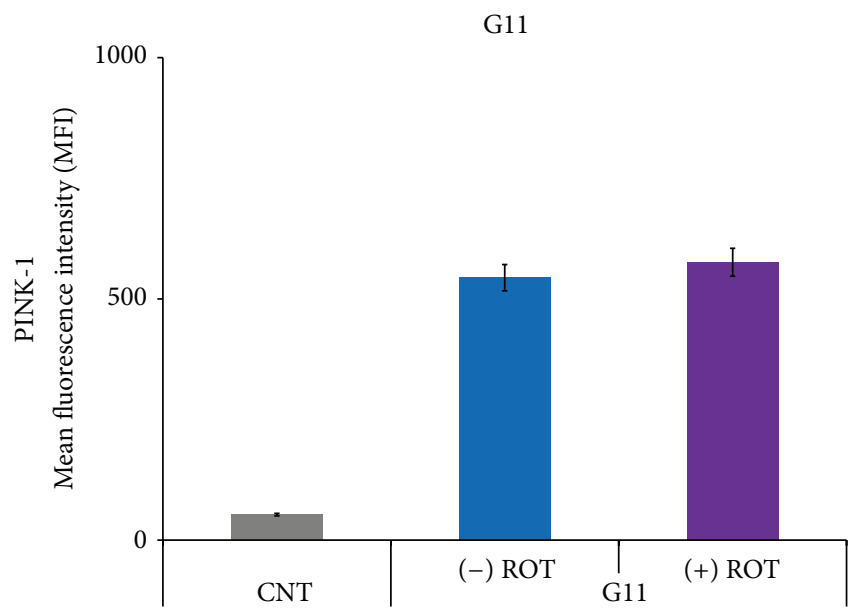

(e)
G55

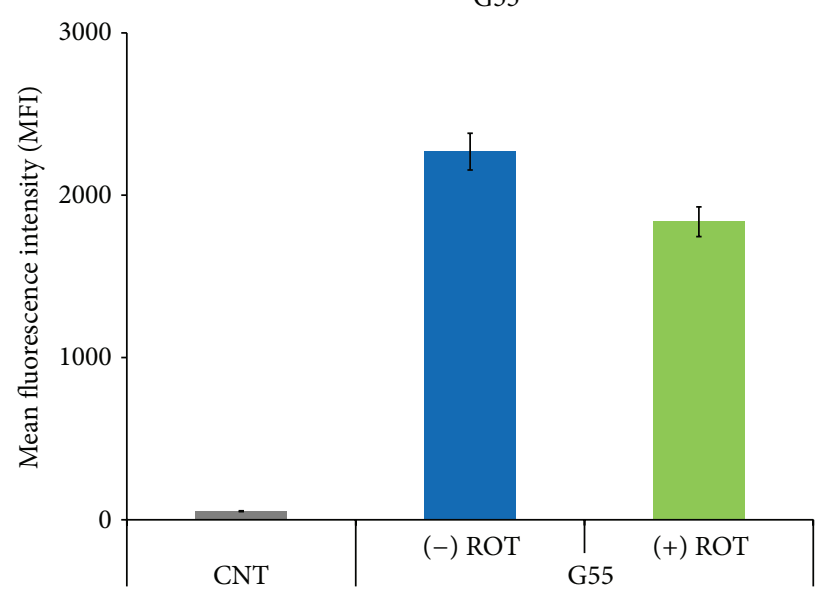

(b)

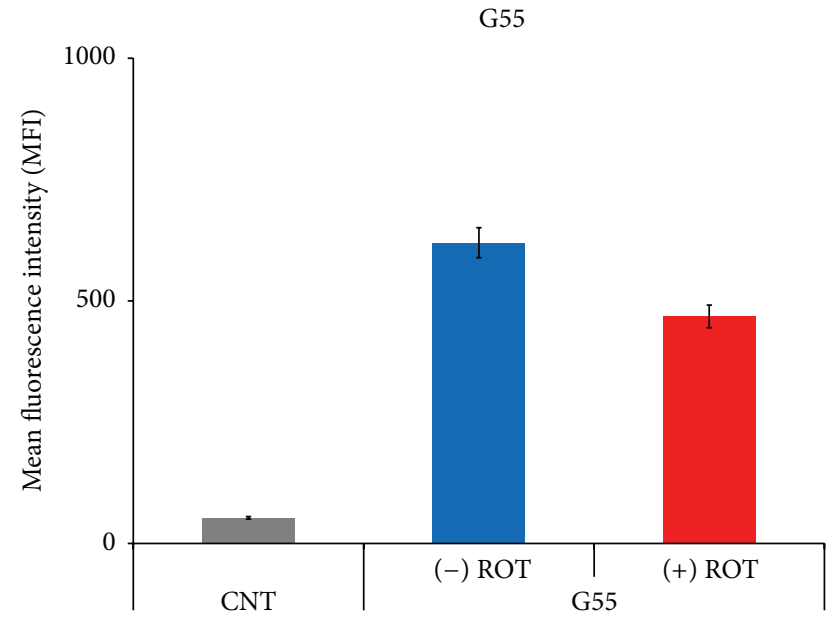

(d)

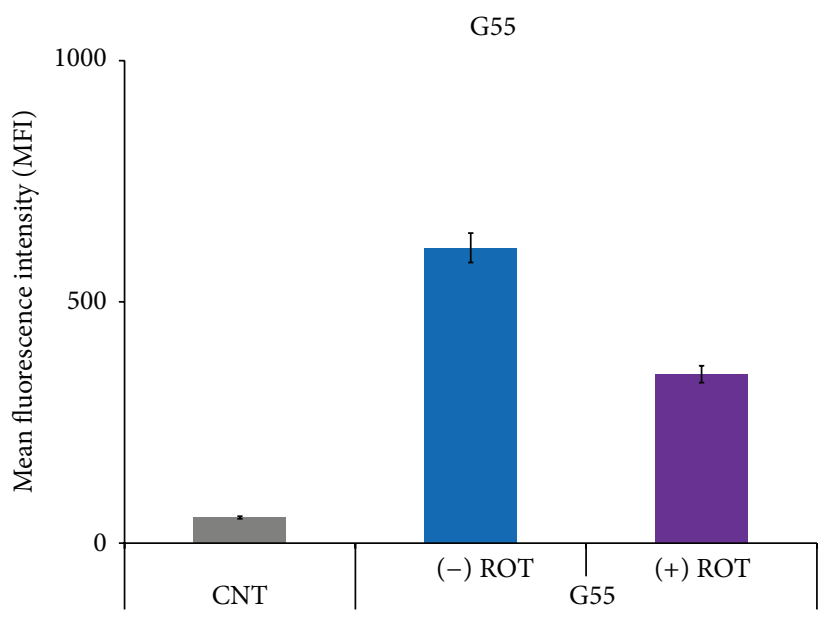

(f)

FIGURE 4: Glucose modulates the response of DJ-1, Parkin, and PINK-1 in Jurkat cells exposed to ROT. Leukemia cells were left untreated or exposed to $(50 \mu \mathrm{M})$ ROT in G11 or G55 medium for $24 \mathrm{~h}$. Cells were stained with anti-DJ-1 ((a) and (b)), anti-Parkin ((c) and (d)), and anti-PINK-1 ((e) and (f)) antibodies, as described in Materials and Methods. Results are expressed as mean fluorescence intensity (MFI) of Jurkat cells and were compared between treatments from three independent experiments. ${ }^{*} P<0.05$ versus respective control determined by the Student $t$-test. 


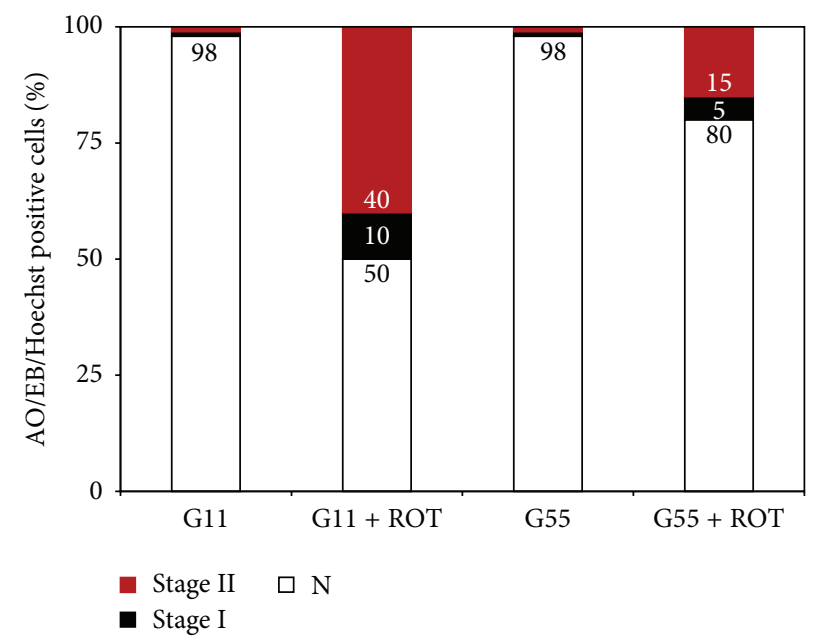

(a)
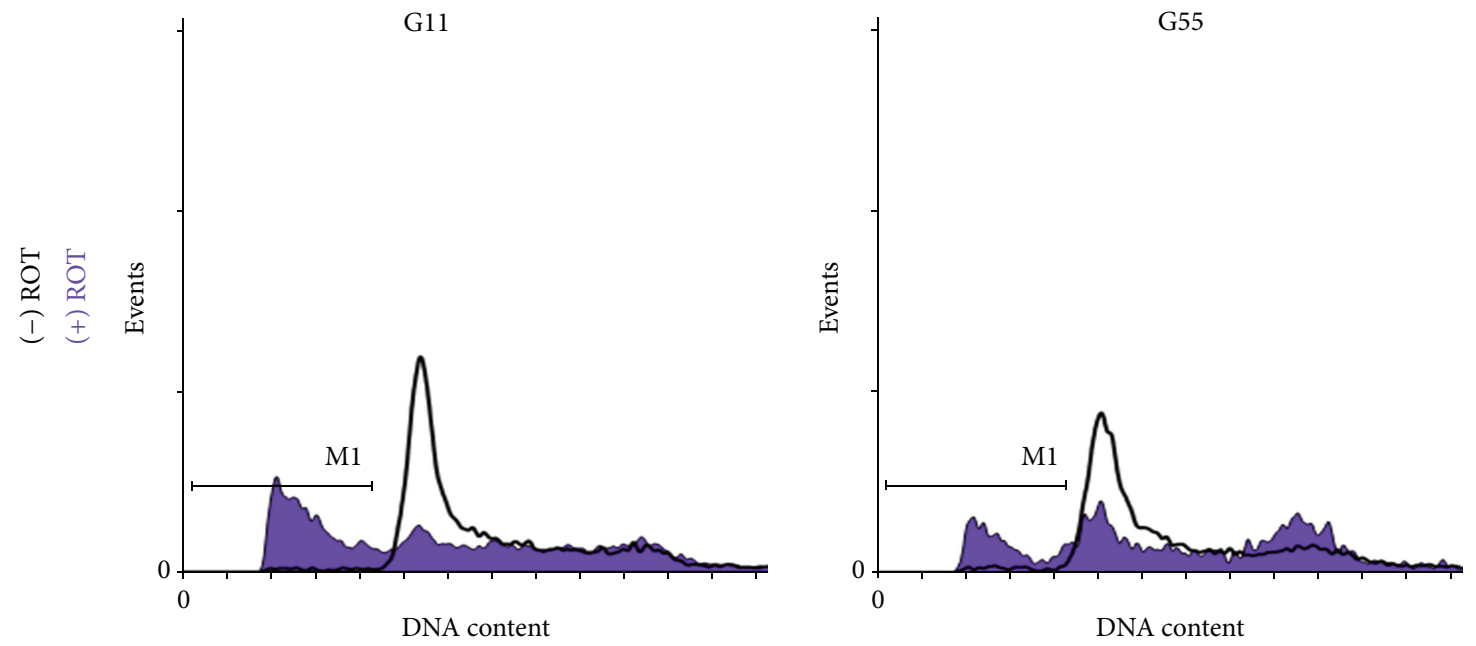

$\square 3 \%$

$\square 2 \%$

口 $41 \%$

ㅁ $19 \%$

(b)
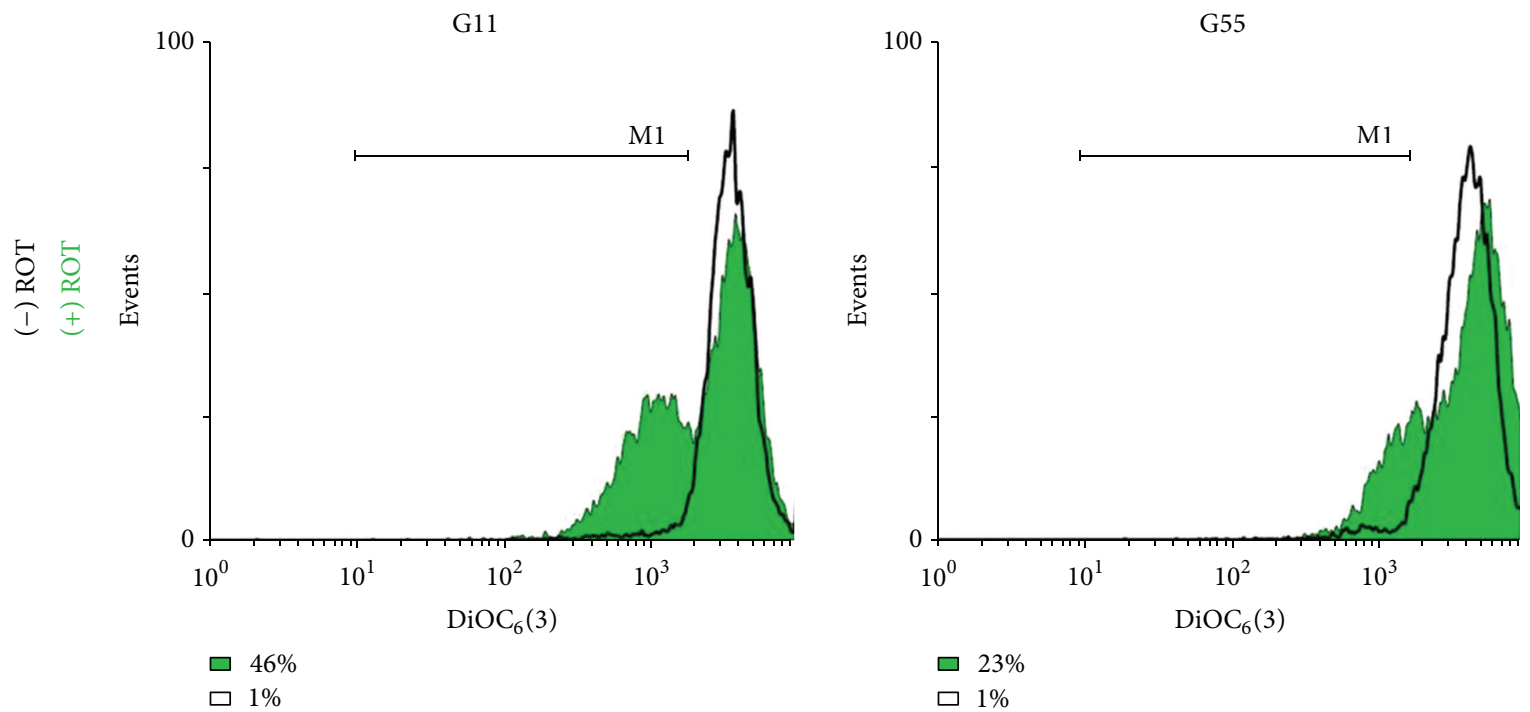

$\square \quad 1 \%$

(c)

Figure 5: Continued. 

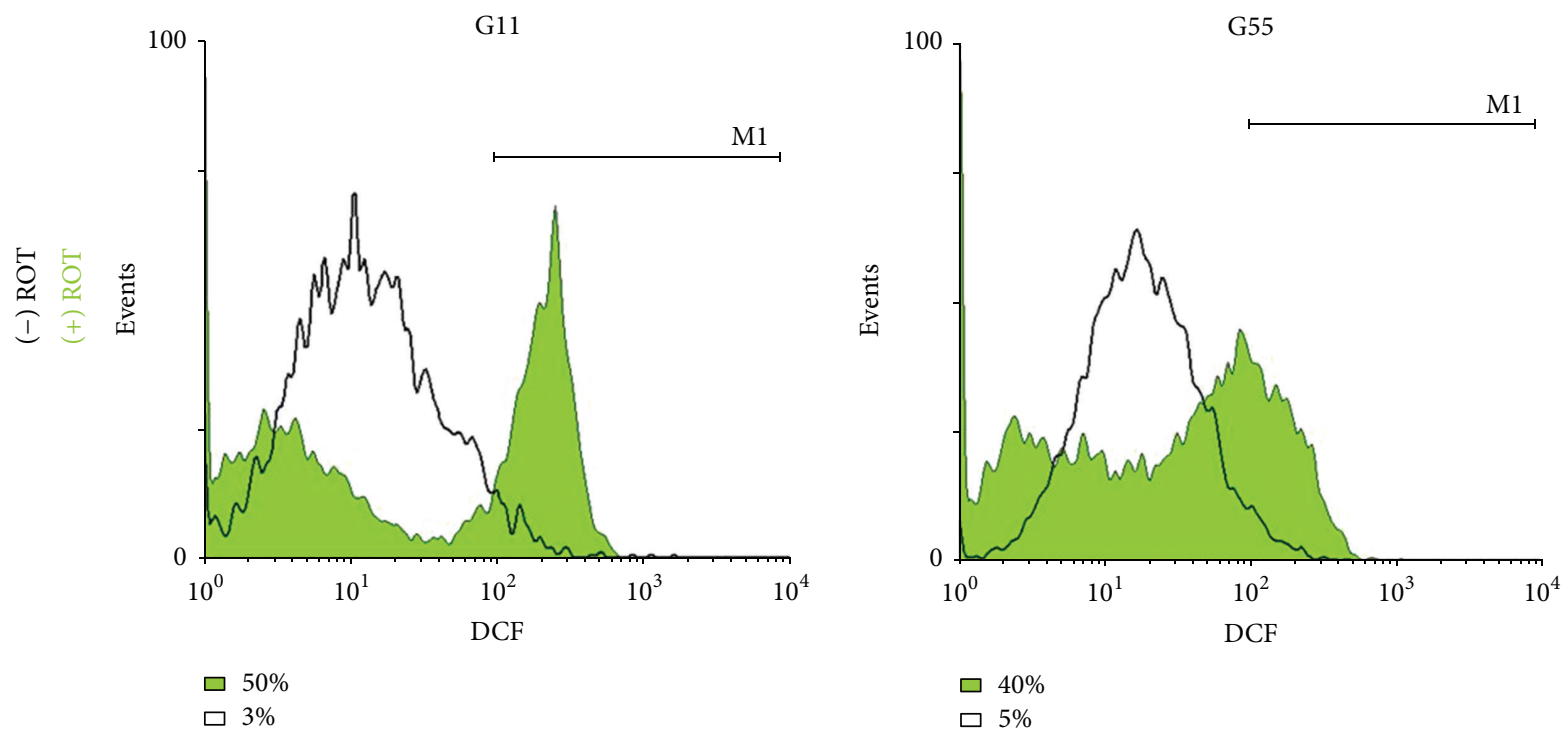

(d)

FIGURE 5: High glucose modulates ROT-induced apoptosis in Jurkat cells. Jurkat cells were left untreated (white box) or treated with (50 $\mu \mathrm{M})$ ROT (purple, dark green, and light green box) in G11 or G55 medium for $24 \mathrm{~h}$. Then after that, cells were evaluated for (a) morphological changes (i.e., normal (white box), Stage I (black box) and II (red box) nuclei morphology) by fluorescence microscopy using AO/EB/Hoechst staining, (b) DNA fragmentation, (c) mitochondrial transmembrane potential, and (d) $\mathrm{H}_{2} \mathrm{O}_{2}$ generation, as described in Materials and Methods. Figures represent one out of three independent experiments andparameter values are expressed as percentage (\%).

of AIF, NF- $\kappa \mathrm{B}, \mathrm{p} 53, \mathrm{c}-\mathrm{Jun}$, and caspase-3 markers and apoptotic nuclear morphology in G11. Furthermore, while ROT induced cytoplasmic DJ-1 protein accumulation and the upregulation of Parkin, PINK-1 protein kinase was unaffected. In contrast, when glucose was present in excess (G55), cell death and/or dysfunctional markers were dramatically $(>50 \%)$ reduced. Taken together, our data suggest that ROT induces apoptosis in Jurkat cells more efficiently in low (G11) than in high (G55) glucose environment by OS molecular mechanism. Several data support this conclusion. First, ROTinduced apoptosis in Jurkat cells was significantly reduced by the antioxidant NAC [26]. Second, $\mathrm{H}_{2} \mathrm{O}_{2}$ was constantly produced by ROT exposure (up to $50 \mu \mathrm{M}$ for $24 \mathrm{~h}$ ). Currently, $\mathrm{H}_{2} \mathrm{O}_{2}$ is considered an intracellular second messenger in several signalling pathways by activating kinases. Interestingly, some reports have demonstrated that $\mathrm{H}_{2} \mathrm{O}_{2}$ induces NF- $\kappa \mathrm{B}$ activation in Jurkat cells either through the spleen tyrosine kinase (Syk) [27] or the $\mathrm{I} \kappa \mathrm{B} \alpha$ kinase complex (IKK) [28]. Noticeably, Jurkat cells treated with ROT induced p65-DAB ${ }^{+}$ nuclei, as an indicator of $\mathrm{p} 65$ activation and translocation to the nuclei. Moreover, pharmacological inhibition of NF- $\kappa$ B with PDTC significantly inhibited the apoptotic morphology under ROT exposure. These data suggest that ROT induces activation and translocation of the NF- $\kappa \mathrm{B}(\mathrm{p} 65)$ probably via the aforementioned $\mathrm{H}_{2} \mathrm{O}_{2}$-induced mechanisms, thus implicating the activation of the transcription factor NF$\kappa \mathrm{B}$ in ROT-induced cell demise. In accordance with other scientific reports (e.g., [29]), our data suggest that NF- $\kappa B$ functions as a sensor of OS linked to cell death signaling. Third, it has been shown that NF- $\kappa \mathrm{B}$ is able to upregulate p53 expression in cells exposed to $\mathrm{H}_{2} \mathrm{O}_{2}$ [30]. Accordingly, it is found that ROT induces p53 $\mathrm{DAB}^{+}$cells with evident morphology of apoptotic nuclei. This observation implies p53 as an important molecule in ROT-induced apoptosis. This conclusion is further supported by the fact that PFT, a specific inhibitor of $\mathrm{p} 53$, was able to significantly reduce ROTinduced apoptotic morphology and $\Delta \Psi_{\mathrm{m}}$ depolarization. Our observations suggest an association between NF- $\kappa \mathrm{B}$ and p53 in Jurkat cells under OS. Finally, inhibition of JNK, reduced activation of c-Jun, and low percentage of cell death in presence of ROT indicates that c-Jun activation is also required for ROT-induced cell death [31]. Collectively, these data suggest that NF- $\kappa \mathrm{B}, \mathrm{p} 53, \mathrm{JNK}$, and c-Jun are critical proapoptotic factors in ROT-induced apoptosis in Jurkat cells.

Apoptosis is a morphological phenomenon as an outcome of the biochemical process taking place at the mitochondria [5]. To avoid potential confusion about the mode of cell death in Jurkat cells with other techniques as reported by Mattes [32], we used one of the most reliable methods to directly visualize apoptotic morphology - the acridine orange/ethidium bromide assay in combination with Hoechst staining. ROT-induced morphological apoptotic features (i.e., stage I and II nuclei fragmentation) in Jurkat cells. These observations suggest that ROT induces apoptosis via 2 pathways which run in parallel: AIF-dependent and caspase3-dependent mechanisms associated with mitochondrial depolarization. This assumption is supported by a significant reduction of apoptosis in Jurkat cells treated with specific caspase-3 inhibitor NSCI, and caspase-3/AIF immunohistochemical positive nuclei $\left(\mathrm{DAB}^{+}\right)$staining. These results comply with the notion that caspase-3 is required for DNA fragmentation and some of the typical morphological changes of cells undergoing apoptosis such as shrinkage, blebbing, 


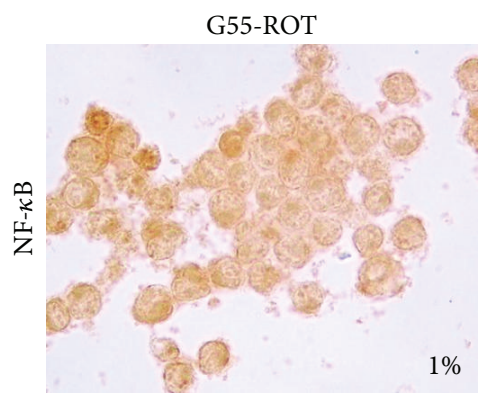

(a)

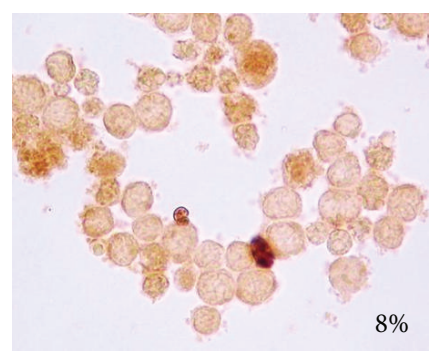

(d)

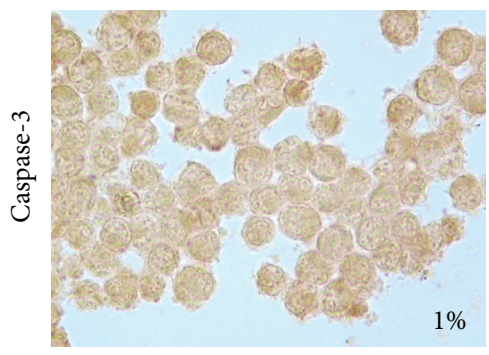

(g)

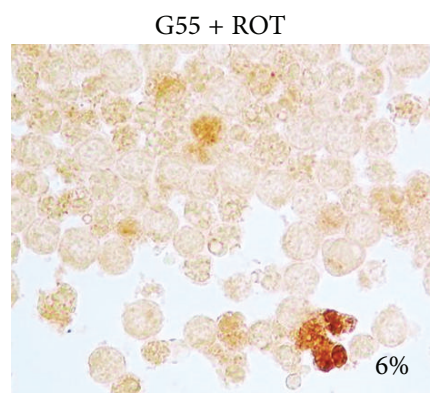

(b)

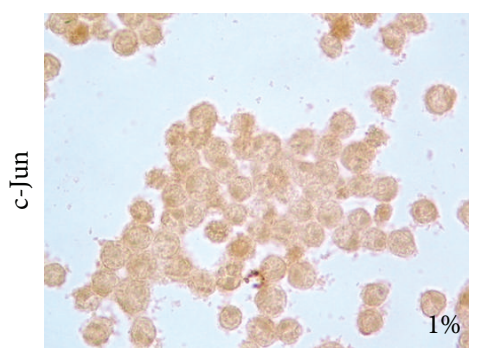

(e)

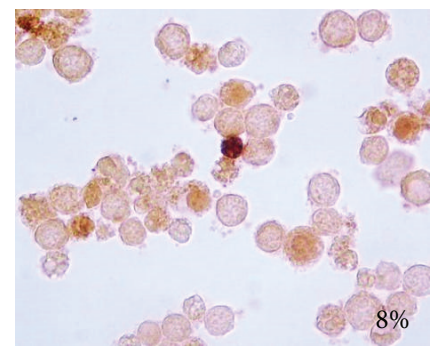

(h)

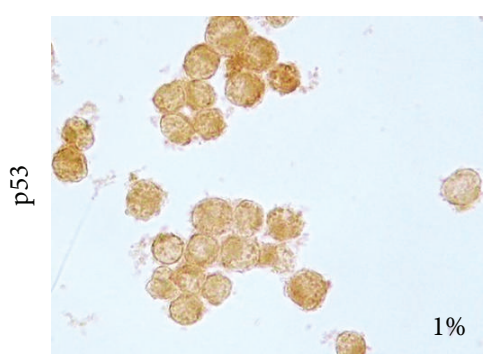

(c)

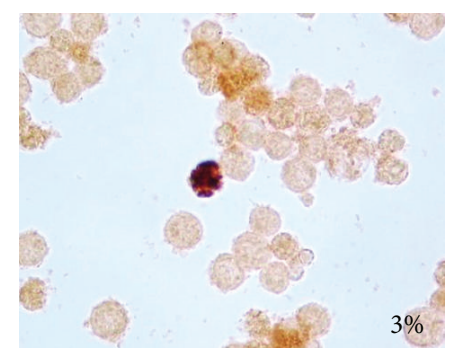

(f)

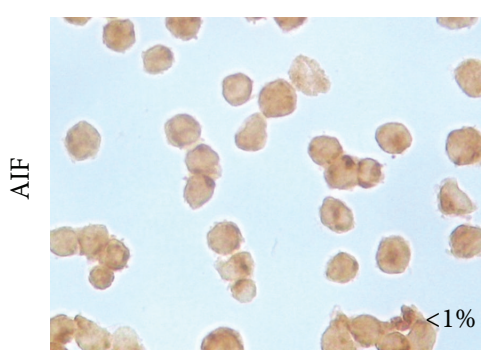

(i)

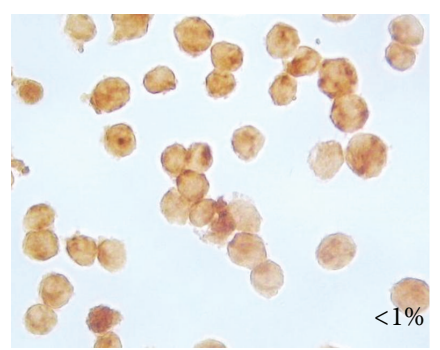

(j)

FIgURE 6: High glucose reduces the activation of the transcription factors, apoptosis-inducing factor, and caspase-3 in Jurkat T cells exposed to ROT. Leukemia cells were left untreated ((a), (c), (e), (g), and (i)) or exposed to (50 $\mu \mathrm{M})$ ROT ((b), (d), (f), (h), and (j)) in G55 medium for $24 \mathrm{~h}$. Cells were stained with anti-NF- $\kappa$ B-p65 ((a) and (b)), anti-p53 ((c) and (d)), anti-c-Jun ((e) and (f)), anti-caspase-3 ((g) and (h)), and anti-AIF ((i) and (j)) antibodies, as described in Materials and Methods. Notice that positive nuclei (dark brown color) reflect their nuclear translocation/activation and appear to correlate with the apoptotic nuclear morphology. Magnification 500x ((a)-(j)). Insets: percentage of positive DAB staining.

and the appearance of nuclei fragmentation in packed round masses, while AIF is required for chromatin fragmentation (for a review, see [33]). Remarkably, we observed neither cytoplasmic vacuolization, nor swelling of the cell, nor mild clumping of nuclear chromatin on cells treated with ROT. Our findings strongly suggest that Jurkat cells die by apoptosis rather than by other modes of cell death. In conclusion, ROTinduced apoptosis proceeds in a domino-like mechanism triggered by $\mathrm{O}_{2}{ }^{\bullet-} / \mathrm{H}_{2} \mathrm{O}_{2}$, which in turn activates $(\gg)$ kinases $>\mathrm{NF}-\kappa \mathrm{B}$, JNK (>c-Jun) $>$ p53 $\gg \Delta \Psi_{\mathrm{m}}>$ caspase-3, AIF $>$ chromatin condensation (stage I), and nuclei fragmentation (stage II).

ROT induces massive cytoplasmic aggregation of DJ-1 in Jurkat cells cultured in G11 compared to untreated cells in either G11 or G55 milieu. These findings are in agreement with the notion that $\mathrm{H}_{2} \mathrm{O}_{2}$ may be able to modify the structural 


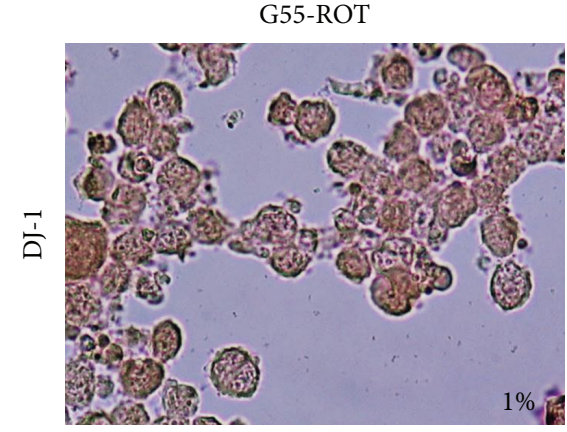

(a)

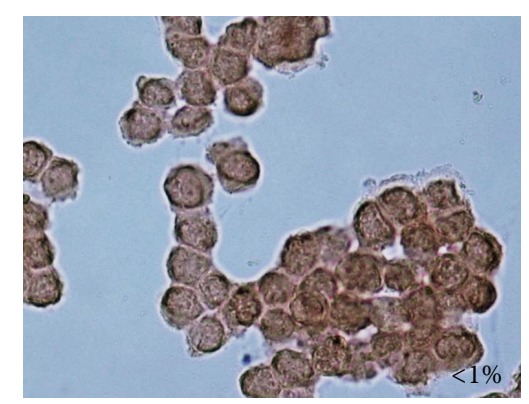

(d)

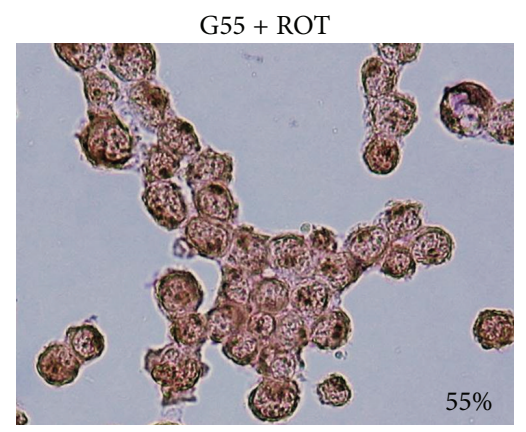

(b)

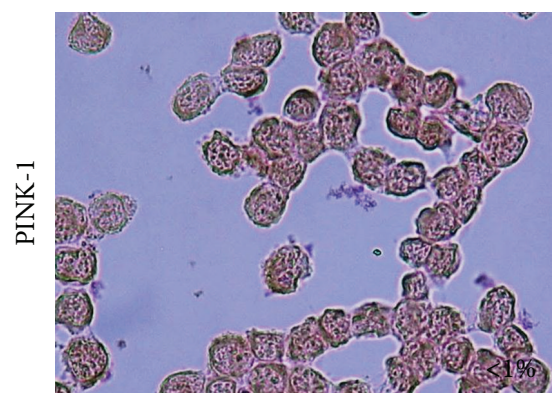

(e)

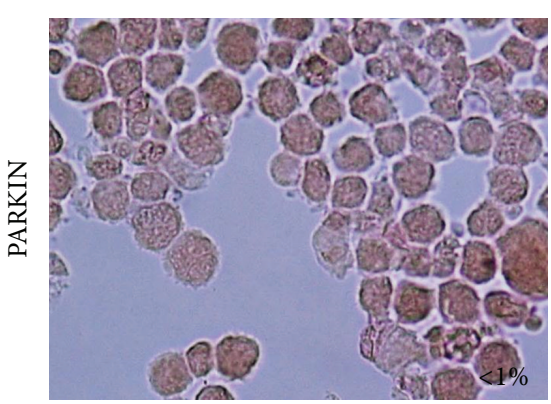

(c)

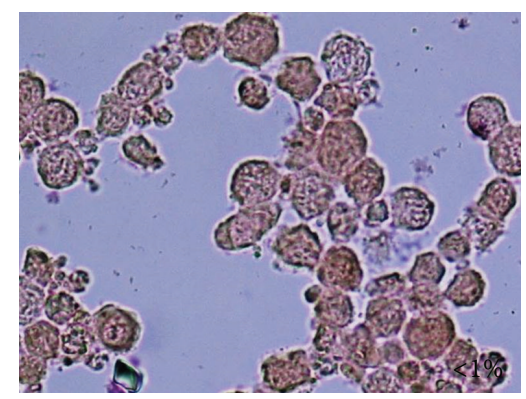

(f)

Figure 7: High glucose reduces DJ-1 aggregation in Jurkat T cells exposed to ROT. Leukemia cells were left untreated ((a), (c), and (e)) or exposed to $50 \mu \mathrm{M}$ ROT ((b), (d), and (f)) in G55 medium for $24 \mathrm{~h}$. Cells were stained with anti-DJ-1 ((a) and (b)), anti-Parkin ((c) and (d)), and anti-PINK-1 ((e) and (f)) antibodies, as described in Materials and Methods. Notice that positive aggregates (dark brown color) reflect their cytoplasmic localization. Magnification 800x ((a)-(f)). Insets: percentage of positive DAB staining.

disposition of DJ-1 [34]. Indeed, it has been reported that $\mathrm{H}_{2} \mathrm{O}_{2}$ is able to oxidizing Cysteine ${ }_{106}$ residue into cysteine sulfonate $\left(\mathrm{Cys}_{106}-\mathrm{SO}_{3}{ }^{-}\right)$, thereby provoking DJ-1 aggregates [35]. However, whether this oxidative modification has a functional role in DJ-1 is unknown. Despite this drawback, several data suggest that $\mathrm{Cys}_{106}$ is required for DJ-1 to confer cellular protection against OS [36]. Current evidence suggest that under basal conditions, DJ-1 (intact $\mathrm{Cys}_{106}$ ) might function as an antioxidant protein by either scavenging relatively low $\mathrm{H}_{2} \mathrm{O}_{2}$ concentrations or performing other prosurvival ancillary functions (e.g., as chaperone). Under moderate $\mathrm{H}_{2} \mathrm{O}_{2}$ exposure, oxidized DJ-1 (cysteine-sulfinate $\mathrm{Cys}_{106}-\mathrm{SO}_{2}^{-}$) protein might function as an inhibitor of either proapoptotic proteins (e.g., apoptosis signal regulating kinase-1, ASK-1; p53) by preventing buildup of $\mathrm{H}_{2} \mathrm{O}_{2}$ in mitochondria [37] or of the upregulation of $\gamma$-glutamylcysteine ligase-the rate-limiting enzyme in the glutathione (GSH) biosynthetic pathway. This last assumption is compatible with our observation that NAC, an antioxidant and precursor of GSH, protects Jurkat cells against ROT. However, under extreme or constant $\mathrm{H}_{2} \mathrm{O}_{2}$ generation, such as by ROT, further oxidation of DJ-1 (cysteine-sulfonate $\mathrm{Cys}_{106}-\mathrm{SO}_{3}{ }^{-}$) elicits loss of structure and aggregation [34]. Because DJ-1 is a sensitive protein towards oxidation by $\mathrm{H}_{2} \mathrm{O}_{2}$, this protein may constitute a marker of cellular stress.

Accumulating evidence suggests that Parkin and PINK-1 may play a role in maintaining mitochondrial function and in preventing $\mathrm{OS}$ [38]. We found that $\mathrm{ROT} / \mathrm{H}_{2} \mathrm{O}_{2}$ upregulates Parkin expression [39], most probably through p53 transcriptional regulation [20]. Our results indicate that ROT induces the differential expression of Parkin and PINK1 proteins. What role does Parkin play in ROT-induced apoptosis? Because phosphorylation of Parkin by PINK-1 activates Parkin E3 ligase function, which in turnactivates NF- $\kappa \mathrm{B}$ signaling through the $\mathrm{I} \kappa \mathrm{B}$ kinase/NF- $\kappa \mathrm{B}$ pathway $[21,22]$, we speculate that the PINK-1/Parkin interaction might amplify the NF- $\kappa \mathrm{B} / \mathrm{p} 53$ death signal axis. Therefore, ROT induces a vicious cycle wherein $\mathrm{H}_{2} \mathrm{O}_{2}$ indirectly triggers PINK-1, which in turn activates $(>)$ Parkin $>$ NF- $\kappa$ B $>$ p53 $>$ Parkin. Our findings suggest that PINK-1/Parkin might be important target proteins to accelerate cell death in Jurkat cells when treated with pro-oxidant drugs.

Recently, it has been shown that glucose starvation (GS) induces OS and apoptosis ( $85 \%)$ through AIF- and caspase3 dependent mechanisms [18]. Here, we found that excess glucose (G55) significantly reduces ROT-induced apoptosis $(\sim 20 \%)$ in Jurkat cells. Accordingly, the signaling death markers (NF- $\kappa \mathrm{B}, \mathrm{p} 53)$, executer (caspase-3, AIF), antioxidant (DJ-1), and mitochondria maintenance (Parkin, PINK-1) proteins diminished $(>50 \%)$ compared to cells treated with ROT in G11. Our results suggest that high glucose promotes stress resistance against $\mathrm{ROT} / \mathrm{H}_{2} \mathrm{O}_{2}$-induced apoptosis in Jurkat cells. How do cells manage to become resistant to ROT-induced apoptosis in G55? When cells are exposed to 


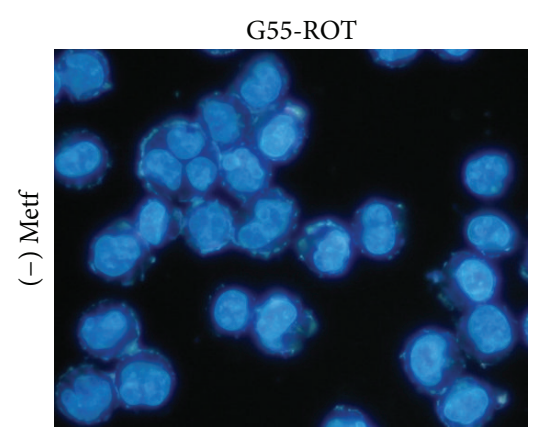

(a)

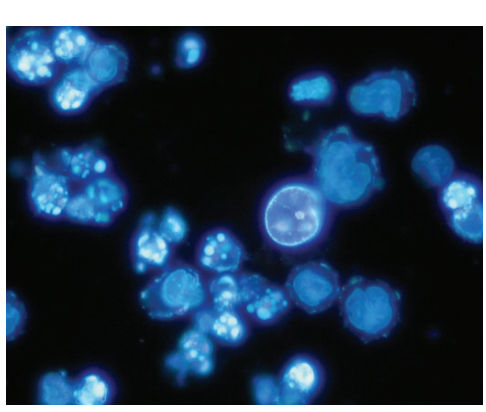

(d)

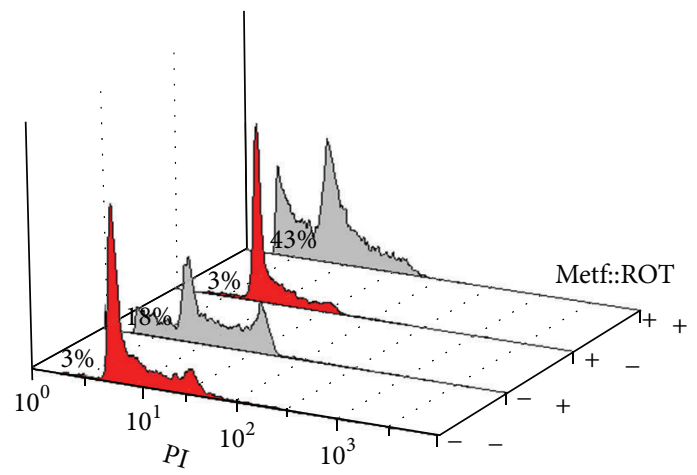

(f)

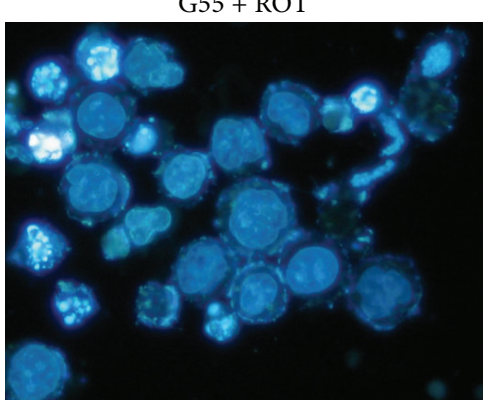

(b)

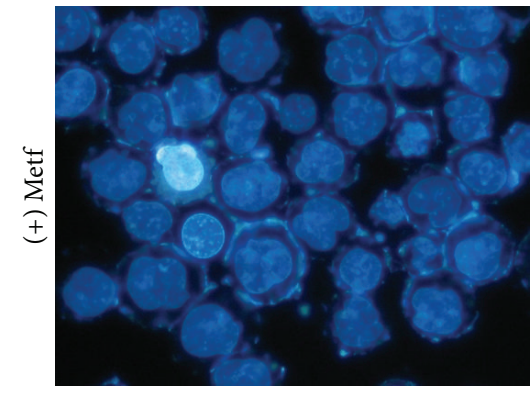

(c)

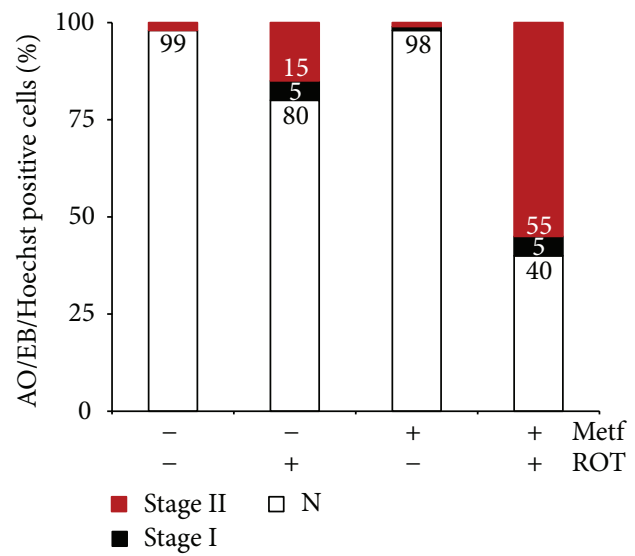

(e)

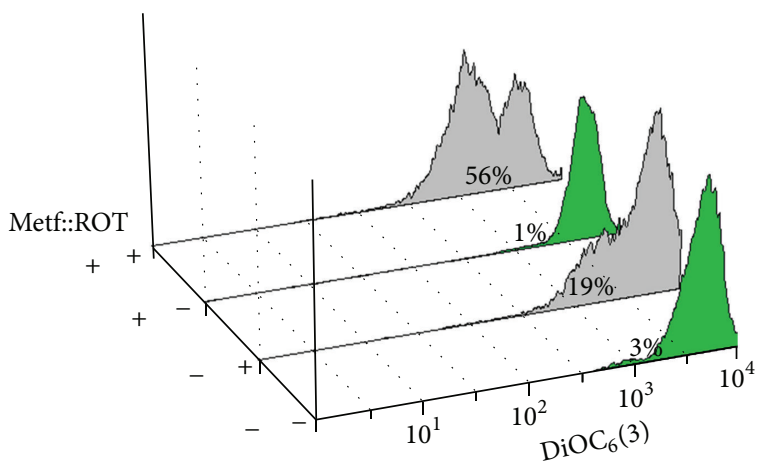

(g)

FIGURE 8: Metformin sensitizes Jurkat cells against ROT exposure in high glucose (G55) condition. Leukemia cells were left untreated ((-) Metf, (-) ROT), exposed to (+) ROT (50 $\mu \mathrm{M})$ alone or in combination of metformin in G55 medium for 24 h. Then after that, cells were evaluated ((a)-(d)) and (e) quantified for morphological changes (i.e., Stage I and II nuclei morphology) by fluorescence microscopy using AO/EB/Hoechst staining, (f) DNA fragmentation assay. (g) Mitochondrial transmembrane potential assay, as described in Materials and Methods. The values in (e) are expressed as mean from three independent experiments. Magnification 1000x ((a)-(e)).

high OS stimuli, glucose can be routed through the pentose phosphate pathway (PPP) to generate the reducing agent $\mathrm{NADPH}$, which preserves the intracellular levels of GSH, one of the most abundant intracellular antioxidant (for a review, see reference [40]). For this reason, cells with an active PPP are protected against OS and ROS-generating xenobiotics such as ROT. Therefore, alteration in energy metabolism by availability of glucose strictly correlated with degree of resistance to class 5 mitocan. However, whether high glucose affects the response of ALL cells to other mitocans (e.g., class $1-4,6-8)[8]$ is still unknown. Further investigation is warranted to solve this issue. Interestingly, we found that the glucose-lowering drug metformin sensitizes Jurkat cells to ROT in G55 milieu. Grimaldi et al. [41] have found that metformin alone induced apoptosis and autophagy in ALL cells including Jurkat cells. Others have reported that metformin exerts its antidiabetic effects through inhibition of complex I of the mitochondrial respiratory chain [42]. 


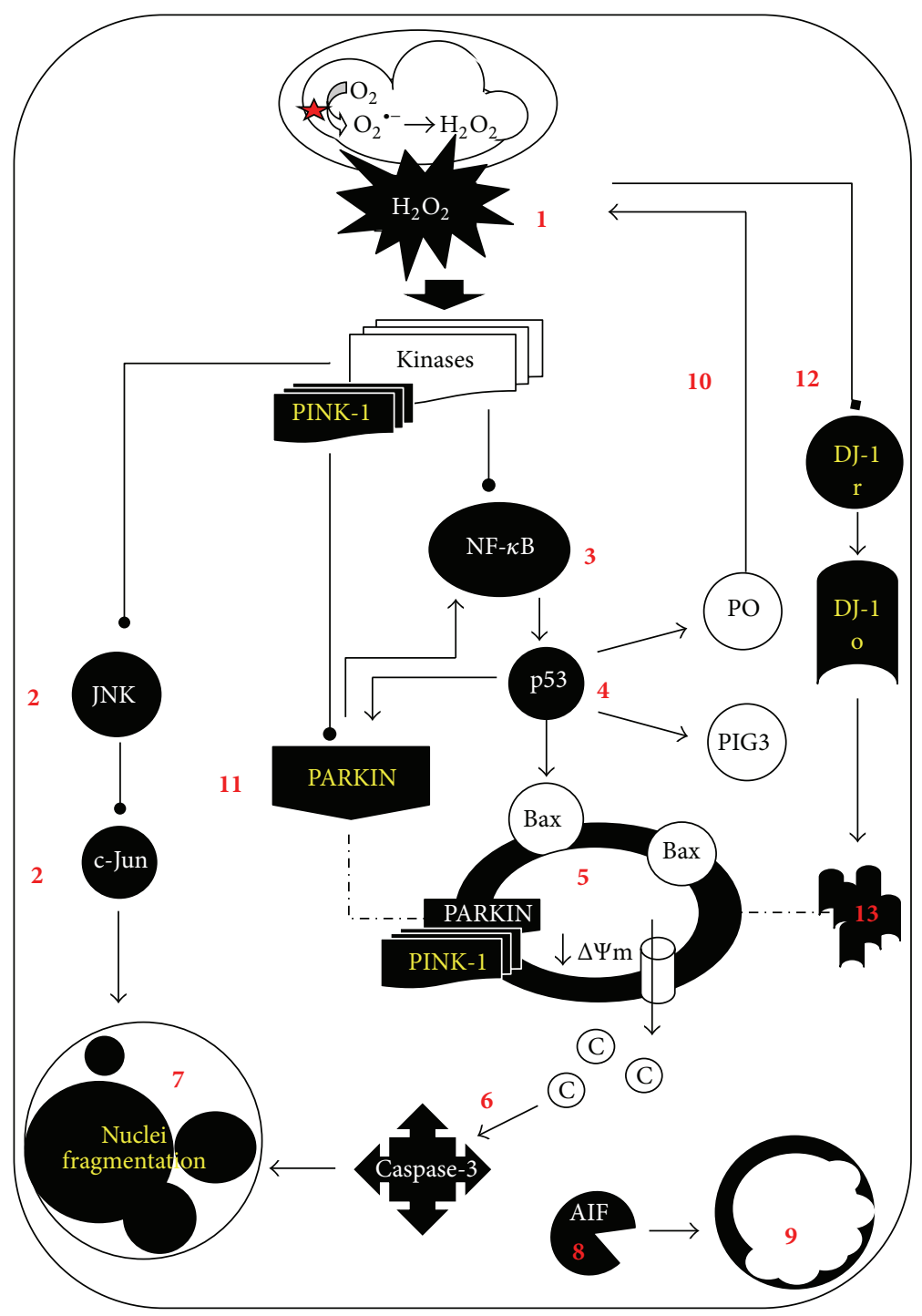

FIGURE 9: Schematic model of the major molecular events by which rotenone provokes apoptosis in Jurkat cells under different glucose conditions. Rotenone inhibits complex-I (NADH: ubiquinone oxidoreductase) ensuing overproduction of superoxide anion radicals $\left(\mathrm{O}_{2}{ }^{--}\right)$ which dismutate enzymatically (by superoxide dismutase, SOD) or nonenzymatically into hydrogen peroxide $\left(\mathrm{H}_{2} \mathrm{O}_{2}\right)$. This last compound freely diffuses through mitochondrial membranes to cellular cytoplasm (1). $\mathrm{H}_{2} \mathrm{O}_{2}$ may in turn activate one or several kinases (e.g., the mitogenactivated protein kinase kinase kinase 1, MEKK1; spleen tyrosine kinase, Syk; apoptosis signal regulating kinase-1, ASK) which can directly or indirectly activate both JNK/c-Jun (2) and NF- $\kappa \mathrm{B}(3)$ via phosphorylation of the I $\kappa \mathrm{B} \alpha$ (i.e., the repressor of NF- $\kappa \mathrm{B}$ ). Once NF- $\kappa \mathrm{B}$ is active, it translocates into the nucleus and transcribes p53 protein (4). In turn, p53 transcribes proapoptotic proteins (e.g., Bax) which are able to permeabilize mitochondria (5), thus promoting the activation of caspase-3 (6), which signals DNA fragmentation ((7), stage II nuclei fragmentation), and chromatin fragmentation ((9), stage I nuclei fragmentation) as a result of the apoptotic-inducer factor (AIF) protein action (8). Additionally, p53 can establish two independent but complementary vicious cycles. It can transcribe pro-oxidant proteins (e.g., p53-induced gene-3 (PIG3), proline oxidase (PO), (10), which generate more $\mathrm{H}_{2} \mathrm{O}_{2}$ (1) amplifying the initial $\mathrm{H}_{2} \mathrm{O}_{2}>$ kinases $>$ NF- $\kappa \mathrm{B}>\mathrm{p} 53$ cell death signaling. p53 can also transcribe Parkin protein (11), which is phosphorylated by the autophosphorylated PINK-1 protein, to further activate NF- $\kappa \mathrm{B}$ (3), thus amplifying the NF- $\kappa \mathrm{B}>$ p53 > Parkin death axis. The overproduction of $\mathrm{H}_{2} \mathrm{O}_{2}$ also causes DJ-1 (12) oxidation (DJ-1 o) of Cysteine ${ }_{106}$ residue into cysteine sulfonate $\left(\mathrm{Cys}_{106}-\mathrm{SO}_{3}{ }^{-}\right)$. This chemical reaction might change the structural conformation of DJ-1 into protein aggregates (13). However, when cells are cultured in high glucose concentration (e.g., $55 \mathrm{mM}$ glucose) in presence of ROT, they are able to properly mount an antioxidant response (e.g., probably via pentose phosphate pathway (PPP) to increase GSH by NADPH generation). Hence, functional mitochondria and normal nuclei morphology are preserved.

However, we found that cells exposed to metformin alone were morphologically and metabolically normal, according to $\mathrm{AO} / \mathrm{EB} /$ Hoechst staining, DNA fragmentation, and $\Delta \Psi_{\mathrm{m}}$ assay in both glucose conditions. Our data indicate therefore that the toxic effect of metformin may not involve inhibition of Complex I in Jurkat cells, at least under the present experimental conditions. Noticeably, metformin in presence of ROT in G55 dramatically induces apoptosis and 
nonapoptosis cell death. These data suggest that metformin in combination with Complex-I inhibitors might be a useful therapeutic strategy in hyperglycemic ALL patients [43].

In summary, we provide mechanistic evidence explaining the toxic effect of ROT in Jurkat cells under 2 different glucose conditions (Figure 9). ROT induces $\mathrm{O}_{2}{ }^{--} / \mathrm{H}_{2} \mathrm{O}_{2}$ generation, mitochondrial depolarization, NF- $\kappa \mathrm{B}, \mathrm{p} 53$, and $\mathrm{c}-$ Jun transcription factor activation, AIF nuclear translocation, caspase- 3 activation, chromatin condensation (stage I) and nuclei fragmentation (stage II), DJ-1 cytoplasmic aggregates, and upregulation of Parkin, typical characteristics of apoptosis in Jurkat cells cultured in G11 milieu. However, those apoptosis markers were significantly reduced in cells cultured in G55 under similar OS stimuli. Hyperglycemia in patients with leukemia is associated with increased hospital mortality. Here, we provide insight into the signaling and metabolic alterations related with drug response to metabolic milieu analogous to diabetic and nondiabetic situation in patients with ALL. Taken together, our data suggest that combined therapy by using mitochondrial targeted damaging compounds and regulation of glucose (e.g., by metformin) might efficiently terminate leukemia cells via apoptosis in hyperglycemic conditions.

\section{Conflict of Interests}

The authors declare that they have no conflict of interests concerning this paper.

\section{Acknowledgments}

This work was supported by Colciencias Grant no. 1115-54531420 to Marlene Jimenez-Del-Rio and Carlos Velez-Pardo. Miguel Mendivil-Perez is doctoral student at the "Corporacion Ciencias Basicas Biomedicas" program (CCBB) from UdeA. MM-P is founded by Colciencias Doctoral Program 567-2012. The use of the Flow Cytometry Unit, GICIG-SIUUdeA, for technical assistance is acknowledged.

\section{References}

[1] A. Redaelli, B. L. Laskin, J. M. Stephens, M. F. Botteman, and C. L. Pashos, "A systematic literature review of the clinical and epidemiological burden of acute lymphoblastic leukaemia (ALL)," European Journal of Cancer Care, vol. 14, no. 1, pp. 53-62, 2005.

[2] S. R. Lowas, D. Marks, and S. Malempati, "Prevalence of transient hyperglycemia during induction chemotherapy for pediatric acute lymphoblastic leukemia," Pediatric Blood and Cancer, vol. 52, no. 7, pp. 814-818, 2009.

[3] D. Hanahan and R. A. Weinberg, "Hallmarks of cancer: the next generation," Cell, vol. 144, no. 5, pp. 646-674, 2011.

[4] G. Kroemer, L. Galluzzi, P. Vandenabeele et al., "Classification of cell death: recommendations of the nomenclature committee on cell death 2009," Cell Death and Differentiation, vol. 16, no. 1, pp. 3-11, 2009.

[5] L. Galluzzi, I. Vitale, J. M. Abrams et al., "Molecular definitions of cell death subroutines: recommendations of the nomenclature committee on cell death 2012," Cell Death and Differentiation, vol. 19, no. 1, pp. 107-120, 2012.
[6] V. Gogvadze, "Targeting mitochondria in fighting cancer," Current Pharmaceutical Design, vol. 17, no. 36, pp. 4034-4046, 2011.

[7] G. Chen, F. Wang, D. Trachootham, and P. Huang, "Preferential killing of cancer cells with mitochondrial dysfunction by natural compounds," Mitochondrion, vol. 10, no. 6, pp. 614-625, 2010.

[8] J. Neuzil, L. F. Dong, J. Rohlena, J. Truksa, and S. J. Ralph, “Classification of mitocans, anti-cancer drugs acting on mitochondria," Mitochondrion, vol. 13, no. 3, pp. 199-208, 2013.

[9] V. G. Grivennikova and A. D. Vinogradov, "Partitioning of superoxide and hydrogen peroxide production by mitochondrial respiratory complex I," Biochimica et Biophysica Acta, no. 3, pp. 446-454, 1827.

[10] J. S. Armstrong, B. Hornung, P. Lecane, D. P. Jones, and S. J. Knox, "Rotenone-induced G2/M cell cycle arrest and apoptosis in a human B lymphoma cell line PW," Biochemical and Biophysical Research Communications, vol. 289, no. 5, pp. 973-978, 2001.

[11] W.-G. Chung, C. L. Miranda, and C. S. Maier, "Epigallocatechin gallate (EGCG) potentiates the cytotoxicity of rotenone in neuroblastoma SH-SY5Y cells," Brain Research, vol. 1176, no. 1, pp. 133-142, 2007.

[12] Y.-T. Deng, H.-C. Huang, and J.-K. Lin, "Rotenone induces apoptosis in MCF-7 human breast cancer cell-mediated ROS through JNK and p38 signaling," Molecular Carcinogenesis, vol. 49, no. 2, pp. 141-151, 2010.

[13] S. Tada-Oikawa, Y. Hiraku, M. Kawanishi, and S. Kawanishi, "Mechanism for generation of hydrogen peroxide and change of mitochondrial membrane potential during rotenone-induced apoptosis," Life Sciences, vol. 73, no. 25, pp. 3277-3288, 2003.

[14] M. Marella, B. S. Byoung, A. Matsuno-Yagi, and T. Yagi, "Mechanism of cell death caused by complex I defects in a rat dopaminergic cell line," The Journal of Biological Chemistry, vol. 282, no. 33, pp. 24146-24156, 2007.

[15] H. Klintworth, K. Newhouse, T. Li, W.-S. Choi, R. Faigle, and Z. Xia, "Activation of c-Jun N-terminal protein kinase is a common mechanism underlying paraquat- and rotenone-induced dopaminergic cell apoptosis," Toxicological Sciences, vol. 97, no. 1, pp. 149-162, 2007.

[16] S. Ramachandiran, J. M. Hansen, D. P. Jones, J. R. Richardson, and G. W. Miller, "Divergent mechanisms of paraquat, MPP+, and rotenone toxicity: oxidation of thioredoxin and caspase3 activation," Toxicological Sciences, vol. 95, no. 1, pp. 163-171, 2007.

[17] A. Hartley, J. M. Stone, C. Heron, J. M. Cooper, and A. H. V. Schapira, "Complex I inhibitors induce dose-dependent apoptosis in PC12 cells: relevance to Parkinson's disease," Journal of Neurochemistry, vol. 63, no. 5, pp. 1987-1990, 1994.

[18] M. Mendivil-Perez, M. Jimenez-Del-Rio, and C. Velez-Pardo, "Glucose starvation induces apoptosis in a model of acute $\mathrm{T}$ leukemia dependent on caspase-3 and apoptosis-inducing factor: a therapeutic strategy," Nutrition and Cancer, vol. 65, no. 1, pp. 99-109, 2013.

[19] M. Jimenez-Del-Rio and C. Velez-Pardo, "The bad, the good, and the ugly about oxidative stress," Oxidative Medicine and Cellular Longevity, vol. 2012, Article ID 163913, 13 pages, 2012.

[20] C. Zhang, M. Lin, R. Wu et al., "Parkin, a p53 target gene, mediates the role of $\mathrm{p} 53$ in glucose metabolism and the Warburg effect," Proceedings of the National Academy of Sciences of the United States of America, vol. 108, no. 39, pp. 16259-16264, 2011.

[21] I. H. Henn, L. Bouman, J. S. Schlehe et al., "Parkin mediates neuroprotection through activation of $\mathrm{I} \kappa \mathrm{B}$ kinase/nuclear factor- $\kappa \mathrm{B}$ 
signaling," Journal of Neuroscience, vol. 27, no. 8, pp. 1868-1878, 2007.

[22] D. Sha, L.-S. Chin, and L. Li, "Phosphorylation of parkin by Parkinson disease-linked kinase PINK1 activates parkin E3 ligase function and NF- $\kappa \mathrm{B}$ signaling," Human Molecular Genetics, vol. 19, no. 2, pp. 352-363, 2010.

[23] H. Liu, M. Wang, M. Li et al., "Expression and role of DJ-1 in leukemia," Biochemical and Biophysical Research Communications, vol. 375, no. 3, pp. 477-483, 2008.

[24] X. Agirre, J. Román-Gómez, I. Vázquez et al., “Abnormal methylation of the common PARK2 and PACRG promoter is associated with downregulation of gene expression in acute lymphoblastic leukemia and chronic myeloid leukemia," International Journal of Cancer, vol. 118, no. 8, pp. 1945-1953, 2006.

[25] C. Rosilio, N. Lounnas, M. Nebout et al., "The metabolic perturbators metformin, phenformin and AICAR interfere with the growth and survival of murine PTEN-deficient T cell lymphomas and human T-ALL/T-LL cancer cells," Cancer Letters, vol. 336, no. 1, pp. 114-126, 2013.

[26] N. Li, K. Ragheb, G. Lawler et al., "Mitochondrial complex I inhibitor rotenone induces apoptosis through enhancing mitochondrial reactive oxygen species production," The Journal of Biological Chemistry, vol. 278, no. 10, pp. 8516-8525, 2003.

[27] Y. Takada, A. Mukhopadhyay, G. C. Kundu, G. H. Mahabeleshwar, S. Singh, and B. B. Aggarwal, "Hydrogen peroxide activates NF- $\kappa$ B through tyrosine phosphorylation of $\mathrm{I} \kappa \mathrm{B} \alpha$ and serine phosphorylation of $\mathrm{p} 65$ : evidence for the involvement of $\mathrm{I} \kappa \mathrm{B} \alpha$ kinase and Syk protein-tyrosine kinase," The Journal of Biological Chemistry, vol. 278, no. 26, pp. 24233-24241, 2003.

[28] H. Kamata, T. Manabe, S.-I. Oka, K. Kamata, and H. Hirata, "Hydrogen peroxide activates $\mathrm{I} \kappa \mathrm{B}$ kinases through phosphorylation of serine residues in the activation loops," The FEBS Letters, vol. 519, no. 1-3, pp. 231-237, 2002.

[29] S. K. Radhakrishnan and S. Kamalakaran, "Pro-apoptotic role of NF- $\kappa$ B: implications for cancer therapy," Biochimica et Biophysica Acta-Reviews on Cancer, vol. 1766, no. 1, pp. 53-62, 2006.

[30] C. McNeill-Blue, B. A. Wetmore, J. F. Sanchez, W. J. Freed, and B. Alex Merrick, "Apoptosis mediated by p53 in rat neural AF5 cells following treatment with hydrogen peroxide and staurosporine," Brain Research, vol. 1112, no. 1, pp. 1-15, 2006.

[31] Y.-O. Son, Y.-S. Jang, X. Shi, and J.-C. Lee, "Activation of JNK and c-Jun is involved in glucose oxidase-mediated cell death of human lymphoma cells," Molecules and Cells, vol. 28, no. 6, pp. 545-551, 2009.

[32] M. J. Mattes, "Apoptosis assays with lymphoma cell lines: problems and pitfalls," British Journal of Cancer, vol. 96, no. 6, pp. 928-936, 2007.

[33] I. F. Sevrioukova, "Apoptosis-inducing factor: structure, function, and redox regulation," Antioxidants and Redox Signaling, vol. 14, no. 12, pp. 2545-2579, 2011.

[34] M. A. Wilson, "The role of cysteine oxidation in DJ-1 function and dysfunction," Antioxidants and Redox Signaling, vol. 15, no. 1, pp. 111-122, 2011.

[35] T. Taira, Y. Saito, T. Niki, S. M. M. Iguchi-Ariga, K. Takahashi, and H. Ariga, "DJ-1 has a role in antioxidative stress to prevent cell death," EMBO Reports, vol. 5, no. 2, pp. 213-218, 2004.

[36] J. Blackinton, M. Lakshminarasimhan, K. J. Thomas et al., "Formation of a stabilized cysteine sulfinic acid is critical for the mitochondrial function of the parkinsonism protein DJ-1," The Journal of Biological Chemistry, vol. 284, no. 10, pp. 6476-6485, 2009.
[37] E. Andres-Mateos, C. Perier, L. Zhang et al., "DJ-1 gene deletion reveals that DJ-1 is an atypical peroxiredoxin-like peroxidase," Proceedings of the National Academy of Sciences of the United States of America, vol. 104, no. 37, pp. 14807-14812, 2007.

[38] M. R. Cookson, "Parkinsonism due to mutations in PINK1, parkin, and DJ-1 and oxidative stress and mitochondrial pathways," Cold Spring Harbor Perspectives in Medicine, vol. 2, no. 9, Article ID a009415, 2012.

[39] Y. X. Yang, M. M. K. Muqit, and D. S. Latchman, "Induction of parkin expression in the presence of oxidative stress," European Journal of Neuroscience, vol. 24, no. 5, pp. 1366-1372, 2006.

[40] C. Riganti, E. Gazzano, M. Polimeni, E. Aldieri, and D. Ghigo, "The pentose phosphate pathway: an antioxidant defense and a crossroad in tumor cell fate," Free Radical Biology and Medicine, vol. 53, no. 3, pp. 421-436, 2012.

[41] C. Grimaldi, F. Chiarini, G. Tabellini et al., "AMP-dependent kinase/mammalian target of rapamycin complex 1 signaling in T-cell acute lymphoblastic leukemia: therapeutic implications," Leukemia, vol. 26, no. 1, pp. 91-100, 2012.

[42] M. R. Owen, E. Doran, and A. P. Halestrap, "Evidence that metformin exerts its anti-diabetic effects through inhibition of complex 1 of the mitochondrial respiratory chain," Biochemical Journal, vol. 348, part 3, pp. 607-614, 2000.

[43] C. Rosilio, I. Ben-Sahra, F. Bost, and J.-F. Peyron, "Metformin: a metabolic disruptor and anti-diabetic drug to target human leukemia," Cancer Letters, vol. 346, no. 2, pp. 188-196, 2014. 


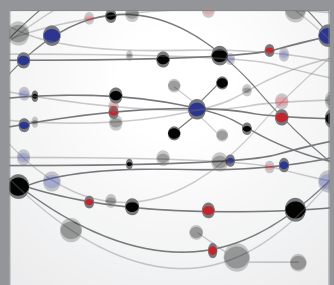

The Scientific World Journal
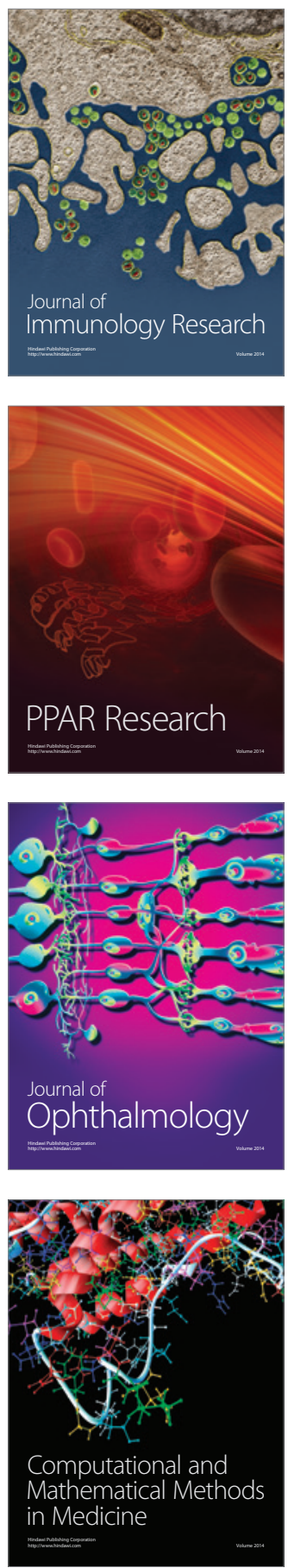

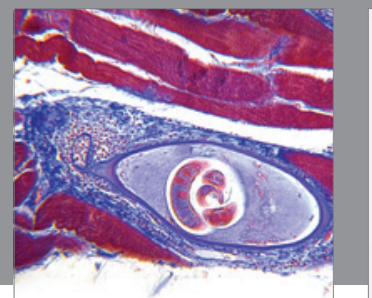

Gastroenterology

Research and Practice
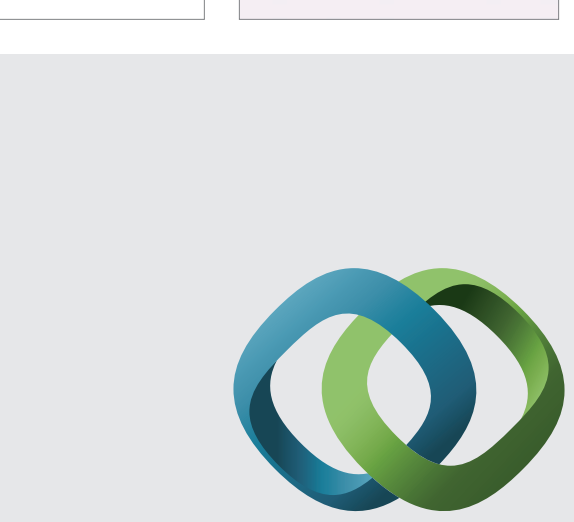

\section{Hindawi}

Submit your manuscripts at

http://www.hindawi.com
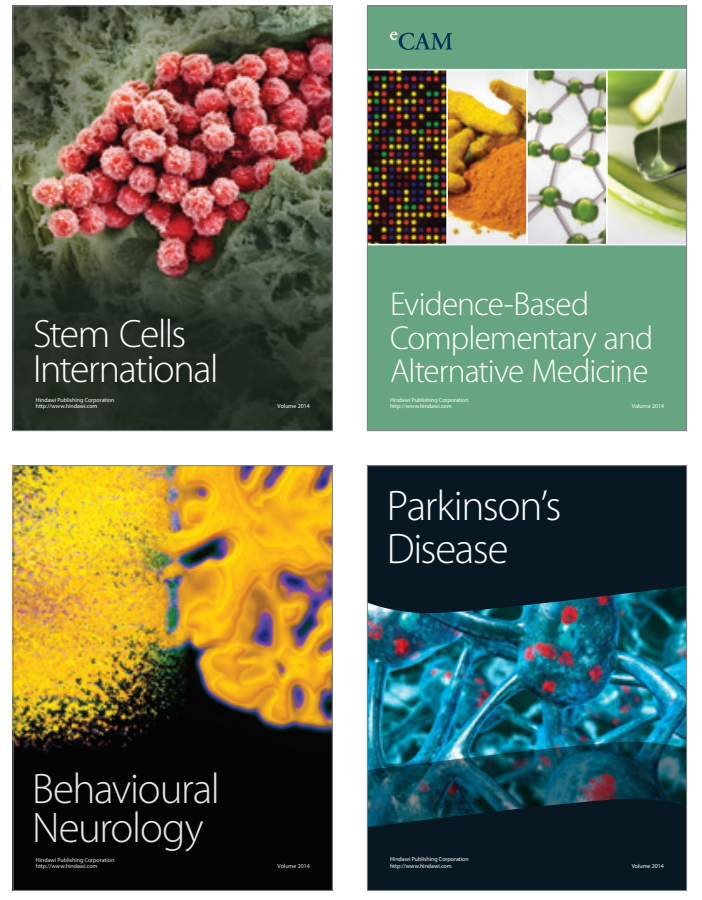
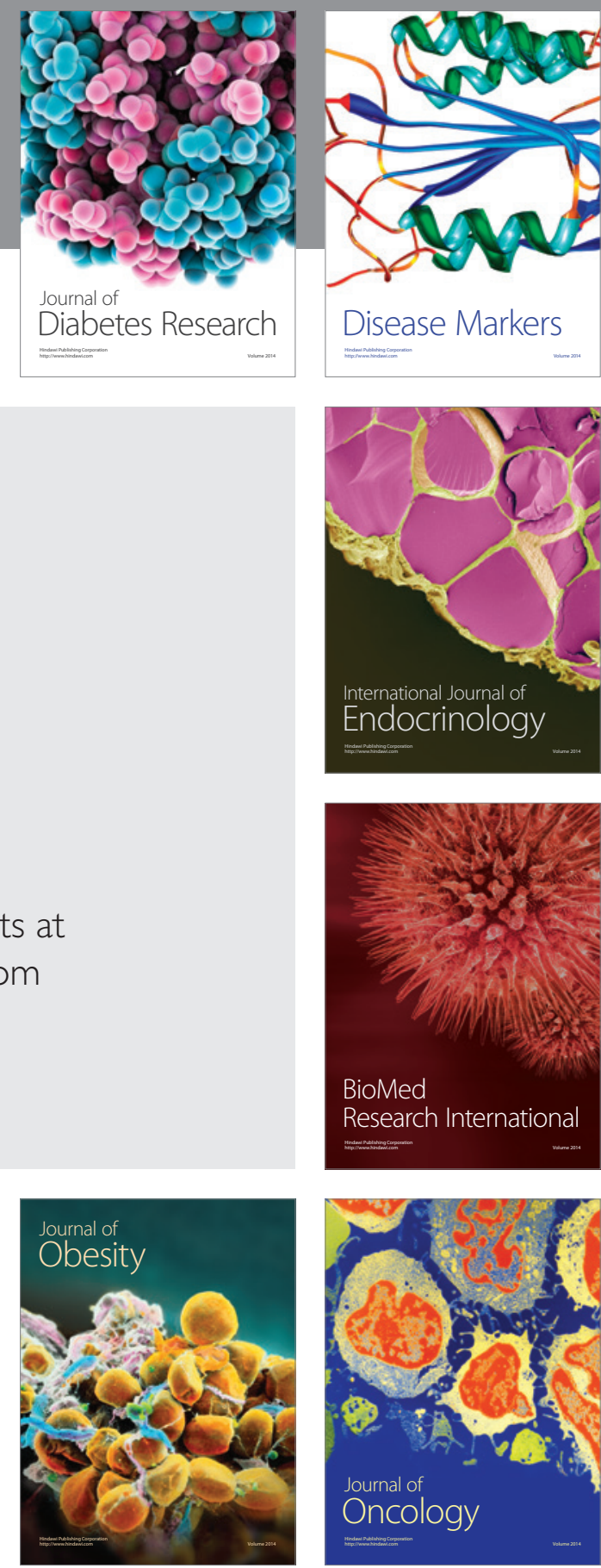

Disease Markers
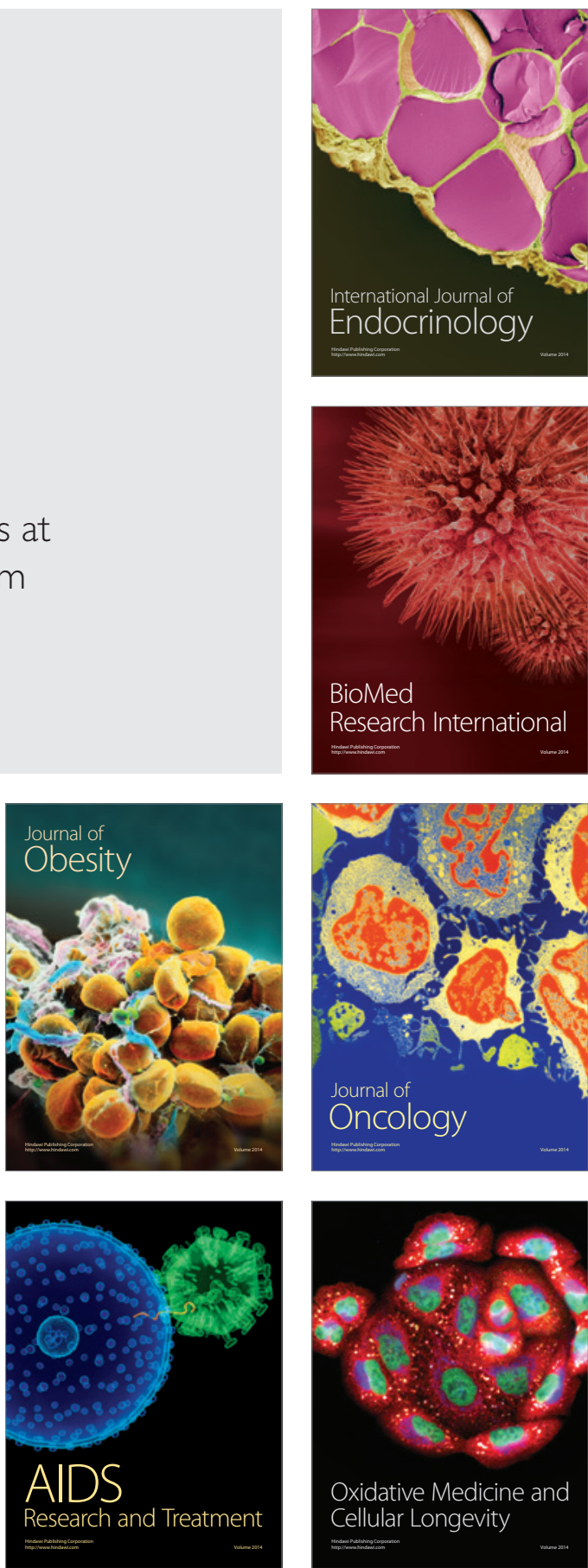